Federal Reserve Bank of Minneapolis

Research Department Staff Report 286

Revised February 2005

\title{
What Determines Productivity? \\ Lessons From the Dramatic Recovery \\ of the U.S. and Canadian Iron Ore Industries Following Their Early 1980s Crisis*
}

\author{
James A. Schmitz, Jr. \\ Federal Reserve Bank of Minneapolis
}

\begin{abstract}
Great Lakes iron ore producers had faced no competition from foreign iron ore in the Great Lakes steel market for nearly a century as the 1970s closed. In the early 1980s, as a result of unprecedented developments in the world steel market, Brazilian producers were offering to deliver iron ore to Chicago (the heart of the Great Lakes market) at prices substantially below local iron ore prices. The U.S. and Canadian iron ore industries faced a major crisis that cast doubt on their future. In response to the crisis, these industries dramatically increased productivity. Labor productivity doubled in a few years (whereas it had changed little in the preceding decade). Materials productivity increased by more than half. Capital productivity increased as well. I show that most of the productivity gains were due to changes in work practices. Work practice changes reduced overstaffing and hence increased labor productivity. Changes in work practices, by increasing the fraction of time equipment was in operating mode, also significantly increased materials and capital productivity.
\end{abstract}

*I thank Ben Bridgman and Sanghoon Lee for excellent research assistance. A large number of people associated with the U.S. and Canadian iron ore industries have provided help, and I thank them: Tom Blaise of Statistics Canada; Bruce Boyd at Natural Resources Canada; Bob Bratulich, district representative for the USW; Wayne Dalke, general manager at Minntac during the middle 1980s; Ann Glumac, past president of the Iron Mining Association of Minnesota; Peter Kakela, the leading industry expert on the North American iron ore industry; William Kirk at USGS; Jared Meyer, who worked at USX headquarters in Pittsburgh and was involved in writing the "Employee Protection/Job Realignment Agreement" in the USW-Minntac BLA; Joe Samargia, president of the USW local at Minntac in the late 1970s; and Jim Swearingen, current general manager at Minntac. Special thanks to Dave Foster, District USW Director, who provided me with a large set of mine contracts. A very large number of colleagues have provided help and encouragement: Avner Ben-Ner, Mark Bils, Francesco Caselli, Steve Davis, Tim Dunne, Lance Fisher, Jose Enrique Galdon, Narayana Kocherlakota, Sam Kortum, Lars Ljungquist, Ellen McGrattan, Diego Restuccia, Dick Todd, and Mark Wright. Valerie Ramey and Jim Tybout provided helpful discussions at conferences. Special thanks to Wulong Gu, Thomas Holmes, Pete Klenow, Ed Prescott, and Richard Rogerson. Finally, I thank the editor Fernando Alvarez and three referees for truly outstanding referee services. The views expressed herein are those of the author and not necessarily those of the Federal Reserve Bank of Minneapolis or the Federal Reserve System. 


\section{Introduction}

For nearly a century following the development of iron ore mining in Minnesota in the 1880s, Minnesota mines, together with a few others in the Great Lakes region, were the sole suppliers of iron ore to the Great Lakes region steel market (that is, the vast steel market lying along the lower rims of Lakes Michigan and Erie and running on toward Pittsburgh). This century-long dominance was primarily attributable to one fact: these mines had significantly lower transport charges to these steel producers than mines outside the region. Large transport costs had meant that non-GreatLakes iron ore was not competitive in the region for nearly a century as the 1970s closed, and there was every reason to believe this situation would persist for many more years.

But it didn't. In the early 1980s, as a result of unprecedented developments in the world steel market, Brazilian producers were offering to deliver iron ore to Chicago at prices substantially below local iron ore prices. Minnesota mines were being challenged in the Great Lakes region steel market, essentially their only market. More generally, the Great Lakes regional producers, that is, the U.S. and Canadian iron ore industries, faced a major crisis that cast doubt on their future. ${ }^{1}$

In response to the crisis, these industries changed how they produced iron ore, dramatically increasing productivity in the process. Labor productivity doubled in a few years (whereas it had changed little in the preceding decade). Materials productivity increased by more than half. Capital productivity increased as well. As a result, the potential foreign competition was pushed out of the Great Lakes region.

I show that most of the productivity gains were due to changes in work practices that governed how production took place. Rigid work practices led to overstaffing. They also led equipment to be in nonproduction mode significant amounts of each day. A loosening of work practices therefore increased labor productivity for two reasons: it led to less overstaffing, and it led to greater

\footnotetext{
${ }^{1}$ Nearly all U.S. and Canadian iron ore production was accounted for by Great Lakes mines (that is, those within a short distance of one of the Great Lakes).
} 
output (as machines ran more continuously). This latter impact, of having machines run more continuously, obviously increased capital productivity. It also increased materials productivity since many materials are consumed even if machines are in nonproduction mode. In answer to my question, "What determines productivity?" the experience of these industries clearly shows first, that competition does, and second, that work practices do.

The experience of these industries presents a great "experiment" to analyze the age-old view that if industries are protected by high tariffs, or restrictions on new entrants, or, as with these industries, the vagaries of geography, their productivity will suffer. The flip side of this view, of course, is that reductions in tariffs and the like will make industries more productive. On this view, the increases in productivity are driven by all producers raising their productivity and not simply by a selection process weeding out inefficient producers. While this view is age-old, and whether or not it's true is a matter of great importance, there is very little work "testing" it. One reason is the difficulty of finding good measures of increased competition. But here the increase in competitive pressure is clear and large. The "experiment" studied here provides strong support for the age-old view. ${ }^{2}$

I now preview the rest of the paper. I show that these industries had been highly protected until the late 1970s. Though the protection was afforded by large transport costs, it can, of course, be thought of as high tariffs as well. I then show that (exogenous) changes in world steel production in the early 1980s dramatically increased competition faced by these industries, changes that were akin to a falling tariff on iron ore. I show that in response to the crisis both industries doubled their labor productivity in a few years. ${ }^{3}$ In Canada, materials productivity increased by 60 percent.

\footnotetext{
${ }^{2}$ Other recent studies about the relationship between competition and productivity include Borenstein and Farrell (1999), Bridgman and Schmitz (2004), Galdón-Sánchez and Schmitz (2002), Holmes and Schmitz (2001), MacDonald (1994), Markiewicz, Rose, and Wolfram (2004), Nickell (1996), Sivadasan (2003), and Symeonidis (2002). Most of these papers look at changes in competition and its influence on productivity. Syverson (2003) examines differences in competition in a cross section of geographically isolated concrete industries and the impact on productivity. Clark (1987) looks at productivity across countries within an industry.

${ }^{3}$ Galdón-Sánchez and Schmitz (2002) show that as a result of developments in world steel production in the 1980s, some national iron ore industries, like the U.S. and Canadian industries, came under tremendous competitive pressure,
} 
For the U.S. industry, materials productivity also increased, but less than in Canada. Total factor productivity (TFP) also soared in the Canadian industry. It grew at nearly two-thirds the rate of labor productivity. Data are not available to calculate U.S. industry TFP.

I show that a long list of conventional factors had only a small impact on labor, materials, and capital productivity $(Y / N, Y / M$, and $Y / K$, respectively). The first four factors would primarily influence industry TFP (and hence $Y / N, Y / M$, and $Y / K$ ). First, perhaps the "best" mines survived. Using mine level data, and a standard labor productivity growth decomposition, I show that closing low productivity mines (and shifting production to high productivity mines) had little impact on industry labor productivity. Second, changes in the scale of production at individual mines also had little impact on productivity. Another top candidate, of course, is improvement in technology. But third, technology changed little in the U.S. and Canadian iron ore industries during the 1980s. Fourth, available evidence indicates that improvements in the average skill of the workforce contributed little to the gains. In sum, conventional factors that might have increased industry TFP, and hence $Y / N, Y / M$, and $Y / K$, had only a small role to play.

I next focus on labor productivity, considering conventional factors that might have led to the increases in materials per hour and capital per hour (which together contributed a small amount to labor productivity growth). Conventional factors had little to do with these increases. Labor did not become expensive relative to materials and capital, which would have led to substitution toward materials and capital. The crisis led to removal of some restrictions in union contracts on what mines could purchase, including some repair parts and some services of off-site contractors. Dropping these restrictions was responsible for a small part of the increase in materials per hour, but only a very small part.

Taken together, these conventional factors led to a modest increase in productivity, but not

while others, like the Australian and Brazilian industries, came under little or none. They show that in the former group productivity soared, while in the latter group it changed little. This paper provides a detailed study of the sources of productivity gains in these former industries. 
the surges experienced in these industries. This leads me to changes in work practices. I label this an unconventional factor since the idea that such changes could have dramatic impacts on $Y / N$, $Y / M$, and $Y / K$ is not found in the economics literature. But they are not an unimportant factor in the business reporting on these industries' recovery. They are typically accorded the central role in the productivity gains. ${ }^{4}$

Before the crisis, labor-management relations in these industries were very adversarial. Work was performed under rigid work practices. Two stand out, both involving repair work. First, machine operators were not permitted to set up, maintain, or perform simple repairs on their machines (or to help repair staff if they were summoned). Second, repair staff had restrictions on their work. There were a large number of repair job classifications, close to 30. A person with a given classification was permitted to complete repair jobs assigned to this classification but not others. After the crisis, there was a thawing of labor-management relations. The situation was obviously dire: 25 percent of the mines in Minnesota were mothballed. The rest were closed for temporary periods as owners considered permanent shutdown. In such a scenario, many miners voluntarily changed work practices. Loosening of work practices also resulted from significant changes in union contracts: labor-management cooperation teams were started, profit-sharing plans were introduced, and formal work rules were changed.

These changes in work practices had a significant impact on productivity. I first sketch some theory where work practices are thought of as restrictions on how firms can use inputs. A well-known work practice in railroads was the requirement that diesel trains carry firemen. This is a classic case of overstaffing. Remove the work practice, and labor productivity increases, though little else. The work practices described above have an overstaffing feature, but much more. When a mine hires repair staff to complete tasks that machine operators could easily perform, this leads to overstaffing.

\footnotetext{
${ }^{4}$ See "Taconite Is Back," Minneapolis Star Tribune, January 8, 1996. See also Marcus and Kirsis, with Kakela (1987, ch. 1, p. 50).
} 
But since the machine operator must wait for the repair staff to travel to the site to complete the task, machines are in nonproduction mode longer than necessary. Detailed job classifications also lead to unnecessary delays. As mentioned above, easing work practices then led to less overstaffing and greater output (as machines ran a larger fraction of a day), increasing $Y / N, Y / M$, and $Y / K$.

I next present evidence that changes in work practices significantly increased $Y / N, Y / M$, and $Y / K$. Consider overstaffing. Repair staffs were a large share of employment at many mines, about 50 percent. Overstaffing was therefore potentially large. And it was, in fact, large. During the crisis, mines did studies indicating that for every five machine operators that were permitted to set up, maintain, and help with machine repairs, repair staff could be reduced by two. In the largest Minnesota mine, repair staff fell from about 50 percent to 25 percent of employment (during which period total employment fell by half and output returned to precrisis levels). I also provide evidence on mine speed. For example, sections in union contracts that introduced changes in work practices explicitly recognized that the changes would lead to greater periods of machinery operation (and hence output). I also provide evidence on overstaffing and "speed" jointly. I show that U.S. mines that changed work practices the most (and had the greatest reduction in overstaffing and the biggest increase in machine usage) had the greatest increases in labor productivity.

In sum, there is little doubt that increased foreign competition spurred the productivity gains in these industries. The evidence is also quite strong that changes in work practices were the primary driver of productivity, there being both indirect (that conventional factors played a small role) and direct evidence. This naturally leads to the question, "Why were work practices not changed before the crisis?" I briefly consider this question in the conclusion.

\section{A Dramatic Increase in Competition}

Here I show that for many years these industries were protected from foreign competition in the Great Lakes region (GLR) steel market. I then discuss the dramatic increase in foreign 
competition in the early 1980 s. ${ }^{5}$

Nearly all U.S. iron ore is produced within a short distance of one of the Great Lakes, in Minnesota (near Duluth) and Michigan (on the Upper Peninsula). For U.S. producers, the GLR steel market was essentially their only market. Canadian producers lie along the Great Lakes and also farther north and east of the Great Lakes, near Labrador City. Canadian ore was sold in the GLR steel market but, given the eastward location of the Labrador mines, it was shipped to Europe and the U.S. east coast as well. Here I focus on describing the increased competition faced by the mines that overwhelmingly sold in the GLR steel market. ${ }^{6}$

Transport charges typically loom large in delivered iron ore prices since a ton often sells for as little as $\$ 10$ at the mine. Potential foreign competitors (that is, non-U.S. and non-Canadian producers) in the GLR market faced large transport costs into the Great Lakes. For many years, these costs provided ample protection to local producers. To see this, consider the entry decision of Brazilian producers, the overwhelming leader in exports in the Atlantic Basin region and the only real potential threat to local producers. During the 1970s, Brazil sent a large share of its production to Europe, where negotiations between Brazilian iron ore producers and European steel producers set iron ore prices in Europe. (See Hellmer 1997.) Call this price $p_{B, E}$ (that is, the price of Brazilian iron ore in Europe). Brazilian producers would have found it profitable to ship iron ore to Chicago, instead of Europe, if the local Chicago price, call it $p_{M, C}$ (that is, the price of Minnesota iron ore in Chicago), net of the ocean transport cost from Brazil to Chicago, call it $t_{B, C}$, exceeded the price per ton in Europe, net of the ocean transport cost from Brazil to Europe, call it $t_{B, E} \cdot{ }^{7}$ This would

\footnotetext{
${ }^{5}$ U.S. and Canadian iron ore production in 1980 was 70.7 and 48.7 million metric tons, respectively. Their combined production amounted to 21.4 percent of world output (noncommunist) in 1980. Employment at U.S. and Canadian mines in 1980 was 18.2 and 13.8 thousand, respectively.

${ }^{6}$ As for the Canadian mines that sold to Europe, Galdón-Sánchez and Schmitz (2002) describe the increased competitive pressure faced by these mines in the 1980 s.

${ }^{7}$ In this discussion I am implicitly assuming that Brazil has a fixed capacity at a point in time and that capacity is expensive to build. This was true in the iron ore industry. For example, Brazil did open a huge mine in the Amazon (the Carajas mine) in the late 1980s, but only after the World Bank agreed to fund the huge infrastructure (like the rail and port facilities) costs of opening the mine.
} 
be true if the Chicago price satisfied $p_{M, C}>\widehat{p}_{M, C}$, where

$$
\widehat{p}_{M, C}=p_{B, E}+\left[t_{B, C}-t_{B, E}\right]
$$

At the Chicago and European prices that prevailed in the late 1970s, the Brazilians would have experienced large losses shifting iron ore from Europe to Chicago, that is, $p_{M, C}<\widehat{p}_{M, C} .^{8}$ There was little fear of entry from Brazil in the GLR steel market. ${ }^{9}$

I say that transport costs provided protection to local GLR producers because the difference in transport costs $\left[t_{B, C}-t_{B, E}\right]$ was large. In particular, it was often one-third to one-half the European price $p_{B, E} \cdot{ }^{10}$ Hence, the large transport charges into the Great Lakes would allow the local price $p_{M, C}$ to climb high, as much as 50 percent higher than the European price, before this ceiling price $\widehat{p}_{M, C}$ was reached.

Foreign competition dramatically increased in the early 1980s. This was precipitated by huge drops in Atlantic Basin steel production. In Figure 1, I plot pig iron production of the United States (in total, and for two exhaustive regions, the Great Lakes region and the rest of the country), Canada, and the three largest European producers combined. (Data sources are discussed in Appendix A. $)^{11}$ Iron ore producers had little influence on the path of pig iron production; it was essentially exogenous to them. ${ }^{12}$ U.S. pig iron production fell dramatically from 1979 to 1982.

\footnotetext{
${ }^{8}$ Marcus and Kirsis, with Kakela (1987) estimate that (in 1978) the price of Brazilian pellets (a type of iron ore, see below) delivered to Chicago would have exceeded the prevailing Chicago price by more than 20 percent. See Exhibit Z-1-18.

${ }^{9}$ This discussion has focused on the potential threat of foreign competition in the 1970s. Before the 1970s, there was absolutely no threat. Brazil was still a very small producer.

${ }^{10}$ To obtain information on $p_{B, E}, t_{B, C}$, and $t_{B, E}$ in equation (1), one typically must pull together data from different sources. One exception is a study of iron ore made by Natural Resources Canada (NRC) in 1994. Though the data are for 1994, they still speak to the main issue at hand. NRC estimates that Brazil to Europe ocean charges were $t_{B, E}=\$ 6.50$ and Brazil to Chicago ocean charges were $t_{B, C}=\$ 24.35$. The delivered price of Brazilian pellets (a type of iron ore, see below) in Europe was $p_{B, E}=\$ 38.03$. The difference in transport charges was 47 percent of the European price. See Gáldon-Sánchez and Schmitz (2002).

${ }^{11}$ Regarding Figure 1, integrated-steel producers turn iron ore into pig iron in the steel-making process, so pig iron is a better indicator of demand for iron ore than steel production (which includes minimill production).

${ }^{12}$ The huge drops in U.S. and European integrated-steel production in 1979-82, and its anemic growth afterward, were driven by many factors, including a major recession, the movement of steel production toward Asia, the growth of minimills, which primarily use scrap and not virgin iron ore, and the accelerated substitution of plastics for steel due to energy price increases. Iron ore producers, whose product makes up a small share of steel production costs (around 10 percent), had little chance to influence these factors influencing steel production.
} 
GLR production fell less than in the rest of the country. The drop in GLR pig iron production was obviously a blow to GLR iron ore producers. But the drop in production on the U.S. east and south coasts (which were supplied by non-U.S. iron ore, including Brazil) and, more important, the drop in European production sent the prices of European iron ore falling. For example, Brazilian dock prices for European iron ore, that is, $p_{B, E}-t_{B, E}$ in (1), fell over 25 percent from 1982 to 1984 (where they remained for the next three years). ${ }^{13}$ This drop in European prices sent the ceiling price $\widehat{p}_{M, C}$ tumbling. The fall in the ceiling price was large enough that Brazilian iron ore was now a real threat in the GLR market. Brazilian iron ore was being offered at a substantial discount relative to local iron ore. ${ }^{14}$ The U.S. and Canadian industries faced the possibility that large portions of them would permanently close. It was immaterial, of course, whether the ceiling price was falling due to tumbling European prices or lower transport charges into the Great Lakes, $t_{B, C}$, so that this episode was akin to an (exogenous) tariff reduction.

Not surprisingly, the dramatic increase in competition cut into large rents that had been earned by groups in these industries before the early 1980s. Consider some of these rents. The Minnesota townships where mines were located charged a tax on each ton of iron ore produced (amounting to about 10 percent of mine value). The United Steelworkers of America (USW), the union that represented hourly and salary workers at the mines in both countries, provided its workers with attractive job packages (as shown below). Though I have little information on local managers (that is, the salaried workers who were not unionized) or owners, they probably did well too. That rents evaporated with increased foreign competition in the early 1980s is clear. Towns

\footnotetext{
${ }^{13}$ These Brazilian iron ore prices can be found on the USGS Web site.

${ }^{14}$ For example, recall Marcus and Kirsis, with Kakela (1987) putting the price of Brazilian pellets delivered to Chicago (in the late 1970s) more than 20 percent higher than local pellets. This report estimates that the price situation completely reversed by the early 1980s, that the price of Brazilian pellets in Chicago would have been more than 20 percent below the prevailing price. Again, see Exhibit Z-1-18. Also, during this period, the Wall Street Journal reported that "importers are offering high-grade Brazilian iron ore to steelmakers in Chicago and Cleveland at $\$ 12$ to $\$ 15$ a ton under the price of Mesabi taconite [Minnesota pellets]." (See "Pocket of Poverty: Minnesota Iron Range," Wall Street Journal, November 26, 1984.)
} 
cut their production tax in the 1980s. ${ }^{15}$ A striking piece of evidence is that a Minnesota mine (Reserve/Northshore) mothballed in 1986 reopened non-union in 1990. I think most industry participants in the late 1970s would have found it nearly impossible to imagine a non-union Minnesota mine a decade later. At the mines where the union remained, the USW and its workers lost significant compensation and benefits. Nominal wages were significantly cut. That the USW provided its workers great benefits before 1980 is attested to by the fact that most of the attrition in the mines during the crisis was from less senior employees, indicating jobs were still in demand and how good the jobs were before the crisis.

To understand why local competition before 1980 was not enough to spur productivity nor to prevent groups from capturing substantial rents, consider the calculus of a potential entrant, say a U.S. steel firm that did not own a mine. ${ }^{16}$ If it opened a new mine, it would have to locate where the ore was (and hence where the existing mines were). In all likelihood, the entrant would be treated (by the towns, the USW, and local managers) just as the existing mines were. That is, there was likely little room to improve productivity and reduce costs. ${ }^{17}$ Hence, local competition could not be expected to spur productivity nor to drive down taxes, and it did not do so. ${ }^{18}$

\section{Increased Competition Met by Huge Productivity Gains}

Here I show that the dramatic increase in foreign competition was met by large increases in labor, materials, and capital productivity in both U.S. and Canadian industries. I then present TFP estimates for Canada's industry. These productivity gains pushed the foreign competition threat

\footnotetext{
${ }^{15}$ See, for example, "Iron Ore Industry May Need More Than Tax Cut," Minneapolis Star Tribune, March 30, 1986.

${ }^{16}$ The iron ore industries in both countries were primarily owned by the largest U.S. steel producers, including U.S. Steel, Bethlehem, and LTV, though there was ownership by non-steel-producing firms (for example, Cleveland Cliffs).

${ }^{17}$ In fact, the Inland Steel Company opened a new mine in Minnesota in the late 1970s as integrated-steel production was forecast to grow strongly. The new mine opened under essentially the same union contract, and faced the same taxes, as the existing mines.

${ }^{18}$ That input suppliers with a monopoly (the towns, USW, and so on) would exploit their position was not lost on investors in Minnesota when the pellet industry was developed in the late 1950s. Investors realized that towns could tax them very heavily once mines were built. So, before mines were built, investors demanded and received changes to the Minnesota constitution limiting taxation on pellets. (See Davis (1964).)
} 
up and out of the Great Lakes region. ${ }^{19}$

Because there are good measures of (real) gross output $Y_{t}$ for the iron ore industry, labor productivity, that is, (real) gross output per hour, is relatively easy to measure. While iron ore is not a homogeneous product, there are only three major types - lump, concentrates, and pellets. In some instances, I am able to look at production by weight (for example, tons) per hour for a given type of iron ore. Otherwise, I can use total tons (the sum across the types) per hour. I also have the typical measure of (real) gross output per hour, where output is industry revenue deflated by a price index (which is likely a more accurate measure of output here than in most industries given the few types of product).

Let me start with production (tons) per hour by type of iron ore. The output and labor productivity of the Minnesota pellet industry is given in Figure 2. Minnesota pellet production accounted for nearly two-thirds (62 percent) of U.S. iron ore production (by weight) in 1980. It fell on the order of 50 percent in 1980-82. While this was a massive drop, the fear was, as the preceding section emphasized, that production would continue to fall as foreign iron ore producers entered the GLR to replace markets they lost elsewhere. Productivity showed little trend over the 1970s. It did vary somewhat with output, tending to be procyclical. The path of productivity in the 1980s was dramatically different from that in the 1970s. The crisis led to a strong upward trend in labor productivity. At its peak in 1987, productivity in Minnesota pellet production was more than twice its 1980 level. $^{20}$

The output and labor productivity of the entire U.S. iron ore industry is given in Figure 3. The pattern of output and productivity for the U.S. industry looks similar to that in the Minnesota pellet industry. The growth in productivity in $1980-87$ is a little less for the entire industry, but

\footnotetext{
${ }^{19}$ At the end of 1980s, the governor of Minnesota, Rudy Perpich, celebrated the tremendous productivity gains in a speech where he noted that Minnesota pellets were now "competitive with Brazilian ore coming into the lakes." (See "Minnesota May Be on the Brink of a Golden Age," Minneapolis Star Tribune, February 21, 1988.)

${ }^{20}$ The quality of Minnesota pellets increased over the 1980s as limestone began to be added to them. (They were called flux pellets.) Adding limestone required, among other things, more labor per ton. Hence, this change would have meant that, everything else equal, labor productivity would fall (though it soared).
} 
it still doubles over this short period. The output and labor productivity of the Canadian iron ore industry is given in Figure 4. The experience of the Canadian industry looks similar to that of the U.S. industry. ${ }^{21}$

The Canadian industry's materials productivity, $Y_{t} / M_{t}$, and capital productivity, $Y_{t} / K_{t}$, are given in Figure 5. I present two capital productivity series, one using capital stock to measure $K_{t}$ (the typical measure) and the other using capital services. The (real) materials $M_{t}$ and (real) capital services series $K_{t}$ only begin in 1981. After initially falling at the beginning of the crisis, materials productivity increased significantly throughout the 1980s. At its peak in the middle 1980s, materials productivity was nearly 60 percent higher than its 1981 level. This surge in materials productivity probably had as large an impact on profitability as did labor productivity's surge, since materials' share of revenue was larger than labor's share. Capital productivity fell at the beginning of the crisis. As with materials, capital productivity trended up over the decade. At its peak in the middle 1980s, capital productivity (using the capital stock series) was 40 percent higher than its 1981 level; with capital services it was 15 percent higher.

For the U.S. iron ore industry, there are no officially published data for $M_{t}$ and $K_{t}$. The lowest level of aggregation for which these statistics are available is the metal mines industry, which includes the copper, gold, and iron ore industries (and a bit more). ${ }^{22}$ However, the U.S. Census Bureau's Census of Minerals Industries (CMI) provides extensive information on materials spending at U.S. iron ore mines at five-year intervals. For many materials, quantities consumed are also provided. From this information, I can take a stab at estimating real materials growth between

\footnotetext{
${ }^{21}$ In Figure 3, output is measured in tons. Using "deflated" industry revenue as the output measure leads to a nearly identical figure. In Figure 4, output is measured using "deflated" industry revenue. Since in Canada the tons and "deflated" industry revenue measures differ by a small amount, I use "deflated" industry revenue since this is likely a better measure. But the measure with tons produces a very similar figure. See Appendix A for a discussion.

${ }^{22}$ The behavior of productivity in the U.S. metal mining industry in the 1980s looks similar to that in the Canadian and U.S. iron ore industries. In particular, over the $1980 \mathrm{~s}, Y / N$ more than doubled, $Y / K$ nearly doubled, and $Y / M$, after initially falling, entered the 1990s 50 percent higher. Metal mining industry statistics can be found on Dale Jorgenson's Web site, in the KLEM data set. Discussion of the U.S. copper industry can be found in Aydin and Tilton (2000), who show that the doubling of U.S. copper labor productivity in the 1980s had little to do with closing inefficient mines.
} 
1982 and 1987. (See Appendix B.) Between these years, I estimate that U.S. materials productivity increased about 25 percent. ${ }^{23}$ The data on capital stock in the CMI are not extensive enough to make estimates of real capital growth.

To estimate the Canadian industry's TFP growth, I make a fairly standard assumption that industry production can be modeled with a Cobb-Douglas production function

$$
Y_{t}=A_{t} F(\cdot)=A_{t}\left(N_{t}\right)^{\theta_{N}}\left(M_{t}\right)^{\theta_{M}}\left(K_{t}\right)^{\theta_{K}}
$$

where $Y_{t}$ is gross output, $A_{t}$ is a TFP parameter, $M_{t}$ is purchased materials (electricity and fuel, plus supplies, plus contract work), $K_{t}$ is capital services, $N_{t}$ is hours of labor, and $\theta_{N}, \theta_{M}$, and $\theta_{K}$ are the elasticities of output with respect to hours, materials, and capital, respectively. With this technology, TFP is simply the product of $Y_{t} / N_{t}, Y_{t} / M_{t}$, and $Y_{t} / K_{t}$ (with each productivity raised to its respective elasticity). ${ }^{24}$ Another way to calculate TFP is from the expression for labor productivity

$$
\frac{Y_{t}}{N_{t}}=A_{t}\left(\frac{M_{t}}{N_{t}}\right)^{\theta_{M}}\left(\frac{K_{t}}{N_{t}}\right)^{\theta_{K}}
$$

What I assume about the $\theta$ s obviously will influence TFP calculations. Here I make the common assumption that the elasticities are equal to the respective input's share in industry revenue. ${ }^{25}$ But, as it turns out, as far as the theme of this paper is concerned, not a lot hinges on this assumption. For example, consider the issue of what drove labor productivity growth. I am not going to argue that conventional factors were important for growth in some of the terms on the right side of equation (3) but not for others. I argue that conventional factors had little impact on any of the three terms. Put differently, I argue below that changes in work practices were the major factor driving each of

\footnotetext{
${ }^{23}$ According to my estimate, the U.S. industry experienced a smaller increase in materials productivity than did the Canadian industry. This may be due in part to what are likely conservative assumptions I made in estimating the U.S. quantity. (See Appendix B.)

${ }^{24}$ Note that I use the capital services series in estimating TFP. If I instead used the capital stock series, TFP growth would be greater.

${ }^{25}$ I let the shares vary over time. Labor's share of revenue varies roughly between 19 and 21 percent. Materials' share of revenue varies more widely, typically between 53 and 63 percent, though mostly in the middle 50s.
} 
the three terms on the right side of (3). If I split growth in labor productivity differently among the three terms, little in my argument is affected.

Canadian TFP estimates are given in Figure 6 (where I choose units so that $A_{t}=1$ in 1981). TFP initially falls but then significantly rises over the middle 1980s. At its peak in the middle 1980s, TFP was 48 percent higher than its 1981 level (and labor productivity 79 percent higher). ${ }^{26}$ In Figure 6, I also plot (for later reference) $Y_{t} / N_{t},\left(M_{t} / N_{t}\right)^{\theta_{M}}$, and $\left(K_{t} / N_{t}\right)^{\theta_{K}}$. Table 1 lists these quantities.

\section{Conventional Factors Play a Small Role in Productivity Gains}

In this section I show that a long list of conventional factors contributed little to gains in $Y_{t} / N_{t}, Y_{t} / M_{t}$, and $Y_{t} / K_{t}$

\section{A. Closing Low Productivity Mines?}

Suppose some mines were much "better" than others, requiring less labor, materials and capital to produce a ton of iron ore. Closing the "worse" mines would then increase industry TFP. While I don't have materials and capital by mine, I do have hours worked and tons produced. If low labor productivity mines were closed, or production shifted toward high productivity mines, then industry labor productivity would increase. An analysis of mine level data for the Minnesota pellet industry, whose output and labor productivity are given in Figure 2, shows that these were small sources of industry labor productivity growth.

Eight Minnesota pellet mines were in operation in 1980, and their output and labor productivity records are given in Figure $7 .^{27}$ The labor productivity pattern at each mine mirrors, fairly

\footnotetext{
${ }^{26}$ Labor productivity in Figure 4 was 100 percent higher at its peak in the 1980s relative to 1980. In Figure 6, I have plotted labor productivity from 1981 onward (since that is when the other variables are first available). Compared to 1981, the peak is 79 percent higher.

${ }^{27}$ Six pellet mines were in operation by the middle 1960s (Butler, Erie/LTV, Eveleth, Reserve/Northshore, National, and Minntac). Two mines began operations at the end of the 1970s (Hibbing and Minorca). As a result of the crisis in the early 1980s, all mines were closed for temporary periods as owners considered their permanent shutdown. Two mines were closed for periods of years, even though both had shown productivity gains. Butler was closed in 1986 . Reserve was closed in 1987 and reopened in 1990.
} 
closely, the industry pattern seen in Figure 2. Here I present a formal labor productivity growth decomposition for the industry. Denote mine and industry labor productivity by $\pi_{i t}=y_{i t} / n_{i t}$ and $\Pi_{t}=Y_{t} / N_{t}=\sum y_{i t} / \sum n_{i t}$, respectively, where $y_{i t}$ is tons of pellets produced and $n_{i t}$ is hours worked at mine $i$. Industry productivity can be expressed as a weighted average of $\pi_{i t}, \Pi_{t} \equiv \sum_{i \in I_{t}} s_{i t} \pi_{i t}$, where $s_{i t}=n_{i t} / N_{t}$. The change in industry productivity between year $t$ and $t^{\prime}$ can be written

$$
\begin{aligned}
\Delta \Pi_{t, t^{\prime}}= & \sum_{i \in C_{t, t^{\prime}}} s_{i, t} \Delta \pi_{i t, t^{\prime}}+\sum_{i \in C_{t, t^{\prime}}}\left(\pi_{i t}-\Pi_{t}\right) \Delta s_{i t, t^{\prime}}+\sum_{i \in C_{t, t^{\prime}}} \Delta \pi_{i t, t^{\prime}} \Delta s_{i t, t^{\prime}} \\
& -\sum_{i \in X_{t, t^{\prime}}} s_{i, t}\left(\pi_{i t}-\Pi_{t}\right)+\sum_{i \in E_{t, t^{\prime}}} s_{i, t^{\prime}}\left(\pi_{i t^{\prime}}-\Pi_{t}\right)
\end{aligned}
$$

where $\Delta$ is the difference operator (that is, $\Delta \Pi_{t, t^{\prime}}=\Pi_{t^{\prime}}-\Pi_{t}$ ), $C_{t, t^{\prime}}$ is the set of mines that operated in $t$ and $t^{\prime}$ (continuing mines), $E_{t, t^{\prime}}$ is the set that operated in $t^{\prime}$ and not $t$ (entering mines), and $X_{t, t^{\prime}}$ is the set that operated in $t$ and not $t^{\prime}$ (exiting mines). There are five terms in the decomposition. Let term $_{j}$ refer to the $j^{\text {th }}$ term. The first term is the increase in industry productivity from continuing mines increasing their productivity at initial hours (the within-mine term). The second term is the increase in productivity resulting from continuing mines with above-average productivity expanding their share of hours relative to below-average productivity mines (the between-mine term). The third term is the cross-mine term. The fourth term is the increase in productivity due to exits. The fifth term is the increase due to entrants (which is zero since there are no entrants).

Table 2 gives information on the decomposition between the base year $t=1980$ and years $t^{\prime} \in\{1981, \ldots, 1995\}$. The first column reports the percentage industry productivity gain between $t$ and $t^{\prime}$, that is, $\frac{\Delta \Pi}{\Pi} \times 100$, while columns two through five present the share of the percentage productivity gains due to terms $j=1,2,3,4$, respectively, that is, $\frac{\operatorname{term} m_{j}}{\Delta \Pi} \times 100$. Table 2 shows that productivity gains due to closing mines were small, never contributing more than 7 percent of the gains and most often nothing. ${ }^{28}$ The major source of industry productivity gains was within-mine

\footnotetext{
${ }^{28}$ Note that the first mine to close, Butler, closed in 1986, and in that year closing mines contributed nothing to growth. That is because Butler's labor productivity was very close to the industry average in the base year 1980
} 
gains, this term never accounting for less than 73 percent of the gains. While the cross-mine and between-mine terms accounted for some gains, from 1990 onward the within-mine gains accounted for over 90 percent of the gains.

\section{B. Gains From Reducing Scale at Continuing Mines?}

Perhaps changes in the scale of production at individual mines increased $Y_{t} / N_{t}, Y_{t} / M_{t}$, and/or $Y_{t} / K_{t}$. By reducing their scale of operation, mines may have increased productivity by, for example, exploiting the best deposits at the mine, leaving marginal deposits unused. ${ }^{29} \mathrm{~A}$ review of mine level data, again from the Minnesota pellet industry, shows that for most mines that remained open, output in the late 1980s was not less than 1980 levels. (See Figure 7.) It was less only at Reserve and Eveleth (and not much less at Eveleth). Reductions in scale were not a source of productivity gains.

\section{New Technology?}

There were no major technological changes in the iron ore industry in the $1980 \mathrm{~s} .{ }^{30}$ There were minor improvements in technology, to be sure, but these contributed only modestly to the productivity gains.

There were certainly lots of minor improvements in technology. Take the Minnesota pellet industry. In the pit where crude ore was mined, there were improvements in blasting techniques. Computers began to be used in dispatching trucks to transport crude ore to the mills for processing.

and because it was a small mine as well. Reserve closed in 1987 and reopened in 1990, when the contribution again returned to zero.

${ }^{29}$ There can be productivity gains, of course, from scaling back production in anticipation that it might cease altogether in a few years. But I am considering the possibility of increasing productivity by reducing output to a new, "permanent" level, and that is why I examine production levels toward the end of the decade. For example, as the crisis began, mines cut back on long-term, preventive maintenance. They also reduced their stripping and clearing operations in the pit. There was little need to prepare new fields for mining of crude ore. Both these changes would lead to increases in productivity but only for a few years. Clearly, repair and stripping would have to resume to previous levels if the mine survived.

${ }^{30} \mathrm{I}$ know there was no major technological change from my study of the industry. But some readers may be interested to know that during the 1980s the world's two leading iron ore producers, Australia and Brazil, experienced very few gains in labor productivity. There clearly was no general technological improvement in the iron ore industry spreading through the world. 
In the mills, grinding processes were improved. Methods were developed to recycle heat that was used to agglomerate the pellets. To make a better pellet, one that required less coke in the blast furnace, mines began to add limestone to the pellet and to experiment with bonding agents to replace bentonite. ${ }^{31}$ In previous versions of this paper, I took particular improvements and argued that their impact on productivity was small. In fact, the last two improvements mentioned above would have led to lower productivity (in terms of tons per hour or tons per unit of material), though a better product. But it would not be practical for me to learn all the small improvements made at the mines (and then attempt to assess their importance together).

I can, however, make two important points about technology (in addition to the fact that there was no major change). First, whatever marginal improvements were made, they were done on the cheap. For example, much new technology is typically embodied in new equipment. New investment spending (relative to gross output) was at all-time lows in both the United States and Canada during the 1980 s. ${ }^{32}$ Not surprisingly, these industries were very cautious about new investment in the $1980 \mathrm{~s}^{33}$

Second, it's of interest to compare technology improvement in these iron ore industries with that in the U.S. steel industry. There is no doubt that the pace of technological change in the U.S. steel industry in the 1980 s was much greater than that in these iron ore industries. ${ }^{34}$ Yet the U.S. steel industry could not match their labor productivity gains. Labor productivity gains

\footnotetext{
${ }^{31}$ See "Taconite Industry Back on Its Feet for Now," Minneapolis Star Tribune, May 14, 1988.

${ }^{32}$ For Canada, I have new investment relative to gross output by year over time. For the United States, I can only calculate this quantity at five-year intervals (when the CMI is available). It is well known that there is large year-to-year variation in investment in industries, so the U.S. data are subject to this caveat, yet it seems pretty clear that the 1980 s was a period of very low investment relative to revenue.

${ }^{33}$ Interviews in the Wall Street Journal with managers of Minnesota pellet mines corroborate this weak investment spending. (See, for example, "US Basic Industry's Health Improves - Reviving Iron Ore Firm Sends Another Fragile Sign," Wall Street Journal, June 9, 1989.) The manager of the Eveleth mine states that "we're hesitant to buy new equipment because of uncertainty about ore demand."

${ }^{34}$ For example, among U.S. integrated-steel producers, the fraction of steel that was continuously cast soared from 20.3 to 67.4 percent of production over the decade. Continuous casting was a major improvement over previous methods. On the "low" end of the steel market, minimills dramatically increased their share of the market. Minimill technology was also a dramatic improvement over previous methods. The steel industry clearly had much more significant improvements in technology than the iron ore industries.
} 
were 103 and 63 percent in the U.S. iron ore and steel industries, respectively. ${ }^{35}$ In line with this paper's theme, while the U.S. steel industry was badly battered in the 1980s, there was no doubt the industry would survive in some form. The same was not true of iron ore.

\section{Increases in Skill?}

A large increase in the average skill of the workforce would increase $Y_{t} / N_{t}, Y_{t} / M_{t}$, and $Y_{t} / K_{t}$. Statistics Canada has developed measures of quality-adjusted labor input by industry. In classifying workers by type, it uses seven age and four education groupings. Quality-adjusted labor input for the iron ore industry fell less in the 1980s than total hours worked, but the differences were small. From 1981 to 1990, quality-adjusted labor input fell 43 percent and hours worked fell 46 percent. So, on the basis of this information, there does not seem to have been much increase in the average quality or skill of workers. ${ }^{36}$

\section{E. Increase in the Price of Labor Relative to Other Inputs?}

So far, I have considered conventional factors that may have increased $Y_{t} / N_{t}, Y_{t} / M_{t}$, and/or $Y_{t} / K_{t}$. Now, I want to focus on factors that may have increased $Y_{t} / N_{t}$. According to the calculations above, increases in materials per hour and capital per hour were only minor sources of labor productivity gain. (See Table 1 and Figure 6.) In the next two sections, I still want to show that conventional factors had little to do with these increases. In this section I consider the possibility that mine labor had become expensive relative to other inputs, thereby leading to substitution toward these inputs and, hence, increasing the materials-labor and capital-labor ratios. There is no evidence that this was the case.

Consider first the price of labor relative to the price of new capital, $p_{N} / p_{K}$, which I plot in Figure 8, together with the capital-labor ratio, $K / N$. From 1972 to 1980, the price of labor

\footnotetext{
${ }^{35}$ These are productivity gains in 1980-88, in the BLS publication, "Productivity Measures for Selected Industries and Government Services," Bulletin 2406, April 1992.

${ }^{36} \mathrm{It}$ is also important to keep in mind that seniority provisions in union contracts had a large influence on who lost jobs at mines. Management could not freely choose who left and who stayed.
} 
increased about one-third relative to the price of capital. During the $1980 \mathrm{~s}, p_{N} / p_{K}$ increased much less slowly. While $K / N$ was relatively flat in the 1970 s, it soared in the 1980 s. ${ }^{37}$ It seems that the large increase in the capital-labor ratio during the 1980s cannot be explained by a dramatic increase in the price of labor relative to capital.

Consider materials next. I have time series data on price and usage of electricity in Canada. Electricity is a large share of materials in these industries. In Figure 9, I plot the price of labor relative to the price of electricity, $p_{N} / p_{E}$, and the electricity-labor ratio, $E / N$, for Canada. There is no trend in the relative price $p_{N} / p_{E}$ over the 1972-90 period. But there was a large increase in the electricity-labor ratio during the 1980s. Again, it seems that this increase cannot be explained by a dramatic increase in $p_{N} / p_{E} \cdot{ }^{38}$

\section{F. Changes in Restrictions on Purchasing Inputs?}

The discussion in the preceding section implicitly assumes that mines were free to purchase inputs. This was not true. Mines faced restrictions in two materials categories: repair parts and contracting out services. As a result of the crisis, some restrictions were eased. The loosening of restrictions likely was responsible for a part of the increase in the materials-labor ratio, but only a small part.

New union contract provisions allowed mines greater freedom in purchasing repair parts that previously were manufactured in-house. This was sometimes referred to as the shelf-item procedure. It was a new provision whereby if a repair part could be found on a shelf, it could be

\footnotetext{
${ }^{37}$ Two items are important to discuss. First, the price $p_{K}$ is the price of new capital and not a measure of the user cost of capital, which I would prefer (but is not available). Second, the time series for both $p_{N} / p_{K}$ and $K / N$ had "spikes" in 1978. The spikes were due to transitory, and unrelated, occurrences. Regarding the $K / N$ time series, there was a strike that year that led to low hours worked $N$ and hence a high $K / N$. Regarding $p_{N} / p_{K}$, the price of labor used in Figure 8 is compensation per hour (which includes wages and fringes). It increased 40 percent between 1977 and 1978, then fell 13 percent between 1978 and 1979. Over the same years, wages per hour for production workers increased 9 percent and 12 percent. So, clearly something unusual happened to fringe payments in 1978 to make $p_{N}$ soar.

${ }^{38}$ There are again "spikes" in both time series in 1978. Again, the spike in the relative price is due to something unusual happening with fringe payments in 1978. I am not sure about the spike in $E / N$. Note that $E / N$ increased a bit more than $M / N$. (See discussion below.)
} 
purchased. ${ }^{39}$ Other new contract provisions also allowed a limited increase in purchasing services of off-site contractors for repair.

According to the CMI, repair parts and contracting out were a small share of materials spending in 1982, amounting to 6.4 and 2.9 percent of materials, respectively. ${ }^{40}$ Between 1982 and 1987 (the period in which these restrictions were eased), repair parts and contracting out increased to 8.0 and 5.6 percent of materials spending, respectively. But the increase in (real) repair parts and (real) contracting out as a share of (real) materials spending was likely much smaller. Electricity and fuel amounted to 55.8 percent of materials spending in 1982. Electricity and fuel prices fell significantly between 1982 and 1987. Repair parts prices likely increased. Shelf-items were parts that were for sale generally; thus, their prices likely increased. I'm safe, I think, in concluding that changes in contract provisions did not lead to surges in purchases of materials that previously were off limits. ${ }^{41}$

I am exploring, of course, the impacts of loosening contract restrictions on increases in materials per hour and not simply materials. Perhaps hours spent assembling repair parts fell a lot. Suppose after the loosening that a mine could now purchase a particular assembled repair part off the shelf for $x$ dollars. Before it purchased unassembled parts and assembled them on-site. Suppose the unassembled parts cost $y$ dollars, the wages paid to employees assembling the parts $w$ dollars and the depreciation for the machines and tools used in the assembly $d$ dollars. The cost of purchase and assembly was $y+w+d$. Let me assume that $y+w+d$ was not much bigger than $x$ (that is, assembling on-site wasn't too inefficient). Since $x$ was not much bigger than $y$ (that is, the increase in repair part purchases at the mines was small; in particular, it increased from $\$ 42$ million to $\$ 48$

\footnotetext{
${ }^{39}$ As an example of the contract language, here is an excerpt from the Inland/Minorca mine's BLA (August 1, 1986, p. 117): "The Company may purchase standard components or parts or supply items, mass produced for sale generally ('shelf items'). No item shall be deemed a standard component or part or supply item if its fabrication requires the use of prints, sketches or manufacturing instructions supplied by the company or at its behest or it is otherwise made according to Company specifications."

${ }^{40}$ See Appendix B for information on U.S. materials spending.

${ }^{41}$ The increase in spending on repair parts and contracting out were not large because (1) the loosening of restrictions was not great, but perhaps more importantly (2) changes in work practices led to more efficient work on site.
} 
million between 1982 and 1987), which implies that $w+d$ is small. If $w+d$ is small, then the number of employees losing jobs is small. ${ }^{42}$

My assumption could be wrong: assembly on-site could have been inefficient. That is, $y+w+d$ may have been much larger than $x$. Maybe lots of employees lost jobs assembling repair parts. In this case, I would need to assign more credit to the easing of contract restrictions in increasing materials per hour. But if there were huge inefficiencies, mine work practices were likely the culprit. The story would be the same.

I have now explored the contribution of a long list of conventional sources of productivity gain. The conclusion is that these conventional factors contributed only modestly to the surge in productivity in the U.S. and Canadian iron ore industries.

\section{Work Practices and Productivity: Theory}

Here I develop a simple framework to show how restrictive work practices impact productivity.

Work practices are restrictions on how firms can use inputs. For example, work practices might require that machines be manned by at least a certain number of workers. A famous case of such a practice involved the requirement that diesel trains carry firemen. ${ }^{43}$

In the iron ore industries, work practices imposed a sharp separation of maintenance and repair work from production work. Machine operators (production workers) were precluded from setting up their machines, like picking up small supplies and parts incidental to the job. They did not maintain their machines, like tightening nuts and bolts, or replacing fuses, wiper blades, tires, bulbs, batteries and fluids, or jump starting vehicles. They were not involved in repair, like helping repair staff when they were called. After the crisis, machine operators became involved in many of these tasks. ${ }^{44}$

\footnotetext{
${ }^{42}$ For a more formal statement showing this implies the number of job losses is small, see the January 2004 working paper.

${ }^{43}$ When diesel locomotives replaced steam ones, train crews (that is, firemen) were no longer needed to shovel coal into steam engines. But firemen remained on diesels for decades.

${ }^{44}$ A lengthy discussion of changes in these work practices can be found in the Basic Labor Agreement (July 1, 1994,
} 
Work practices also assigned repair staff to a job category or classification. A person with a given classification completed repair jobs assigned to this classification but not others. After the crisis, repair workers engaged in a wider range of repairs. New jobs were created that rolled a large number of previous repair jobs into a single new combined job. An ironworker was to perform the duties that were previously done by boilermakers, riggers, and welders. A millwright's duties were to include those previously assigned to plumbers, pipefitters, welders, and mechanics. In some mines, the number of repair job categories fell from the upper 20 s to the low single digits. ${ }^{45}$

The iron ore industry work practices described above share the overstaffing feature of the fireman case. That is, maintenance and repair staff were employed to complete tasks that machine operators could do. Also, having many repair job categories led to a lack of flexibility in assignment and to overstaffing as well. But they have a very different feature. These work practices slow the system down. By having machine operators wait for maintenance and repair staff, machinery stays in nonproduction mode longer. By having a welder, for example, wait for a pipefitter to complete a pipefitter task that the welder could accomplish, machinery again stays in nonproduction mode longer.

Hence, loosening restrictive work practices in the iron ore case increases labor productivity for two reasons: it leads to less staff but it also increases output as the mine's machines run more continuously. ${ }^{46}$ Having machines run more continuously obviously increases capital productivity. It also increases materials productivity. This is because many mine machines are not shut down as

pp. 158-60) between the USW and the National Steel Pellet Mine.

${ }^{45}$ Another work practice was that tools were designated to be used by certain workers; they were off limits to others. Some tools that were thus designated included chain saws, hammer drills, hoses, screwdrivers, hammers, air tools, magnetic drills, and paint and painting supplies and equipment. Other work practices that changed were where breaks would be taken, how much wash-up time was allowed, and how vacations could be structured.

${ }^{46}$ Below I will present a few more examples of work practices that slowed the mines down. But here let me give an example from the U.S. Class I railroad industry. A story was broadcast on NPR's Weekend Edition, June 16, 2002, about U.S. "short line" railroads. The train engineer (for such a railroad) in the story uses a chainsaw (from his cab) to clear a tree on the track in front of his train. It's mentioned that engineers are not allowed to perform such duties in Class I railroads. Other staff would have to be called to clear the tree. The "other" staff time used to travel to the site (and then back to wherever they were) is obviously wasted time and leads to overstaffing. But probably more important, the train is delayed a certain some number of hours. "Output" over the day is less as a result. 
others are repaired. Hence, fuel and other materials are consumed even when output is not being produced.

These ideas can be presented more formally. Doing so allows me, among other things, to show that changes in work practices can produce time series like that in Figure 6. To save on space, I present this more formal analysis in Appendix C.

\section{Changes in Work Practices Play a Large Role in Productivity Gains}

In this section I provide direct evidence that changes in work practices were important sources of the gains in $Y_{t} / N_{t}, Y_{t} / M_{t}$, and $Y_{t} / K_{t}$.

\section{A. Changes in Work Practices and Labor Productivity}

Changes in work practices increased $Y_{t} / N_{t}$ through two channels: less overstaffing and greater output (from greater mine speed). The first two subsections below present information on overstaffing. The next two subsections present information on overstaffing and mine speed jointly.

Though overstaffing likely occurred in all jobs, the work practice changes were to impact the repair staff most. Repair staffs were a large share of employment in these industries before the crisis. In Minnesota, repair staffs accounted for 50 to 55 percent of total hours at Minntac, 52.5 percent at Inland/Minorca, and 46.5 percent at Eveleth. ${ }^{47}$ So, the overstaffing problem could have been large. The next two subsections show it was.

Mine studies on work practice changes. In the middle 1980s, as part of the process of bargaining over work rule changes, some mines completed studies to estimate the impact of changing repair work rules. In particular, Minntac estimated that for every five machine operators that were made equipment tenders, the repair staff could be reduced by two. ${ }^{48}$ This is a large expected impact

\footnotetext{
${ }^{47}$ The Minntac data (discussed below) are from the St. Louis County mine inspector. The evidence on the Inland/ Minorca and Eveleth mines is from Learmont (1983). The data for Minorca are from 1983; Learmont doesn't specify the year for Eveleth, other than that it is in the early 1980s. Minntac's repair hours (as a fraction of the total) fell sharply in the early 1980s, so these figures for Minorca and Eveleth (which are a year or two into the crisis) may understate their repair staffs prior to the crisis.

${ }^{48}$ An equipment tender was a machine operator who was permitted to maintain and conduct simple repairs on
} 
on repair employment per equipment tender position. ${ }^{49}$ It's important to note the context in which this study was made. The local union and management at Minntac had agreed in principle to reduce the workforce a given amount through loosening work rules. The company then drafted changes in work rules and made estimates of how many jobs would be lost from implementing them. The company obviously had an incentive to underestimate the expected job losses. That this was the case is clear in the Arbitrators Award where the union argued that the company had underestimated the job losses.

Minntac's repair time series. Repair staffs fell disproportionally during the crisis. My best evidence comes from the path of repair hours relative to total hours at the Minntac mine in Minnesota. Fortunately, in reporting hours to safety officials, Minntac reported total hours and hours by three (exhaustive) groups: hours in the pit (nonrepair), in the mill (again, nonrepair), and by repair staff. I plot the share of repair hours in Figure 10. One can see that repair hours (as a percentage of total) fell sharply at Minntac during the crisis. The share was approximately 50 to 55 percent before the crisis; after the crisis, it was approximately 28 percent. ${ }^{50}$ The reduction in repair staff accounted for a large share of employment reduction, well over 75 percent of the total.

Mine variation in work practices: Minnesota. Other evidence on the impact of changes in work practices on $Y_{t} / N_{t}$ is found in variations in work practices within and across mines. This provides information on overstaffing and speed together.

As I mentioned, one Minnesota mine (Reserve/Northshore) actually changed union status over the 1980s. This mine almost certainly had a greater loosening of restrictive work practices

machines. Details concerning this Minntac study can be found in the Arbitration Award that ruled on various aspects of the work rule changes introduced at Minntac. The arbitrator (representing the National Board of Arbitration) was Shyam Das, currently the arbitrator for Major League Baseball.

${ }^{49} \mathrm{It}$ is interesting to note that equipment tenders were discussed as possible sources of large productivity gains in other industries, like the auto industry, that were undergoing work rule changes in the 1980s. For example, Luria (1986) notes that while studies had not been done to assess the effect of work rule changes in the auto industry, "the most sizable cost reductions will probably come from the broadening of job descriptions to enable production workers to set up and maintain their own equipment" (p. 24).

${ }^{50}$ Minntac stopped reporting hours by location to the mine inspectors for a few years during the crisis (though total hours were still reported). That is why there is a "gap" in Figure 10. 
than the other mines (which remained union). It's of interest, then, to compare the evolution of Reserve's productivity to that of the others. Turning to Figure 7, one can see that a few years after its reopening in 1990, Reserve had productivity levels relative to 1980 that were substantially higher than the other continuing mines. After reopening, Reserve's productivity was a factor of four greater than that of its 1980 level, whereas the other mines had productivity levels that were three times or less higher in the early 1990 s as compared to $1980 .{ }^{51}$

Comparing work practice changes across the union mines is difficult. As I mentioned in the introduction, the crisis led to a thawing of labor-management relations and to voluntary changes in work practices. ${ }^{52}$ Work practice changes were driven by these voluntary changes and by formal contract changes (covering profit-sharing, labor-management cooperation teams, and work rules). So, I am left with the problem of how to measure the voluntary changes that took place (that are, by definition, not recorded and not measured). ${ }^{53}$ Given this difficulty, I am not be able to rank union mines by overall changes in work practices. ${ }^{54}$

That said, I would be remiss in not mentioning that Minntac clearly was the mine that most aggressively introduced work rule changes in the 1980s and had the greatest productivity growth. $(\text { See Figure 7. })^{55}$ Also, the National mine, after surviving the 1980s, was again threatened with closure in 1993. New owners bought the mine that year under the condition that there again be

\footnotetext{
${ }^{51}$ Reserve was going through major court battles on environmental issues in the late 1970s, which may have influenced its productivity. Hence, it's also of interest to look at its productivity in the early 1970s relative to other mines and then again in the early 1990s. The same finding holds: Reserve's productivity relative to other mines was higher in the early 1990s than in the early 1970s.

${ }^{52}$ For a story about worker cooperation in productivity improvements, see, for example, "Iron Ore Industry's Best Efforts Fail to Halt Its Decline," Wall Street Journal, November 19, 1986.

${ }^{53}$ Mines may have differed on the extent of voluntary changes because of differences in the age distribution of the work force or other factors.

${ }^{54}$ As a corollary, I cannot say which formal contract changes (for example, work rule changes, profit sharing) were most important in loosening restrictive work practices. For a study comparing the importance of various formal contract provisions, see Ichniowski et al. (1997).

${ }^{55}$ Minntac's work rule changes during the 1980s were far more sweeping than at any other Minnesota mine. The February 1, 1987, BLA between Minntac and the USW contained an "Employee Protection/Job Realignment Agreement" section that stated in part: "The Company shall have a one-time opportunity to reman each affected facility, to be completed by June 30, 1987, including crew composition changes, job realignments and a definition of new jobs and seniority units necessary to achieve the objectives and commitments of this Agreement." No other mine contract in the 1980s had this type of language on work rule changes.
} 
changes in work rules. The surge in National's productivity in 1993-94 was a direct result of these work rule changes. ${ }^{56}$ The National case also illustrates that labor-management cooperation was far from ideal in the 1980s and that there was still plenty of room for productivity improvements.

Mine variations in work practices: Robe River. I next consider the impact of changes in work practices in an Australian iron ore mine, Robe River. In a well-known (in Australia) episode, restrictive work practices were abruptly eliminated at Robe River when new owners replaced senior management of this mine. The Australian industry was not in crisis, but rather the new owners challenged status quo work practices. (No other Australian mine did so for many more years.) This episode differs from the U.S. and Canadian one in the abruptness of the changes (making it easier to isolate the impact of the changes), and also in that the new senior management has written about their experiences. ${ }^{57}$

The production and labor productivity records of Robe River are given in Figure 11. Data are on a fiscal year basis. In contrast to the U.S. and Canadian mines, there was no drop in production in the early 1980s: Australian mines were not in crisis in this period. New owners abruptly announced new work practices on July 31, 1986. The changes were met with resistance by union management and regional government. The small fall in output from 1985-86 to 1986-87 reflects periods when the mine was shut down due to resistance. New management prevailed on most counts in a few months. Production increased by about 75 percent in the next five years. Labor productivity tripled.

\footnotetext{
${ }^{56}$ Commenting on the dramatic increase in National's productivity in 1993-94, Peter Kakela, the leading industry analyst of the Minnesota iron ore industry, said much of the productivity gains came from "simply eliminating people and simply expecting more from the people who were left." (See the article on National Steel in Corporate Report Minnesota, September 1996, p. 56.)

${ }^{57}$ In particular, Charles Copeman, the new general manager at the mine, has written "The Robe River Affair" and "Robe River Revisited," both found on the HR Nicholls Web site. Copeman writes about his experiences because the removal of restrictive work practices was not only unique in the Australian iron ore industry but in Australian industry generally. As he says, "The shock waves reverberated around Australia." In contrast, work practice changes were occurring not only throughout the U.S. and Canadian iron ore industries, but in many U.S. and Canadian manufacturing industries as well.
} 


\section{B. Changes in Work Practices and Materials and Capital Productivity}

When mines are in a nonproduction mode because of breakdowns or stalls in machinery, capital sits idle and materials are still consumed. As a result, changes in work practices that allow mines to run more continuously lead to increases in $Y_{t} / K_{t}$ and $Y_{t} / M_{t}$.

That having machines run more continuously increases $Y_{t} / K_{t}$ is obvious. It would increase $Y_{t} / M_{t}$ if when machines were being repaired, the mines still consumed significant amounts of materials. Hence, I start in the first subsection by arguing that mines indeed do consume a large amount of materials in these situations. Then in the following two subsections I present evidence that changes in work practices did increase the speed of mines and, hence, $Y_{t} / K_{t}$ and $Y_{t} / M_{t}$.

Materials consumed when mines are not operating. A big issue is whether to run machinery when other machinery must be repaired. One issue in deciding to shut machinery down is whether this will save on energy costs. For some machines, energy costs are not saved if machines are shut down for short periods. In pellet mines, furnaces that agglomerate the iron ore are heated to $3,000^{\circ} \mathrm{F}$. Shutting these furnaces down for short periods clearly does not save on energy costs. The fuel to drive these furnaces accounted for 13 percent of U.S. materials consumption in 1982. (See Appendix B.) The diesel trucks that transport ore from the pit to the mill are also typically not shut down for short periods. (Diesel was about 5 percent of materials.) Hence, if mines are in nonproduction mode because some machines need to be repaired, a substantial amount of materials in the form of fuel (in the furnaces and trucks) is still consumed.

Some machinery may be shut down for short periods, like those using electricity generated with someone else's furnace. ${ }^{58}$ Hence, when restrictive work practices were loosened, one might expect tons per unit of furnace fuel and tons per unit of diesel to increase, yet there to be no increase in tons per unit of electricity. This was, in fact, the pattern in both the U.S. and Canadian

\footnotetext{
${ }^{58}$ This is efficient if the electric power generating companies can "smooth" the use of electric power. The mines were typically very large customers of the power companies, and so this put limits on how well the companies could smooth power demand.
} 
industries in the 1980s. (See Appendix B.)

More materials than simply fuel are consumed when mines are in nonproduction mode. For machines that are shut down, this process may lead to increased wear and tear on the machinery. Machinery not shut down consumes materials other than fuel. The furnaces running at these extreme temperatures are continually depreciating and in need of maintenance. There is also depreciation of structures that occurs through time (independent of use), which requires materials to fix.

There are still other materials consumed when output is not produced. For example, materials are consumed by the offices at the mines. Materials are used in the manufacturing of pellets (like chemicals used in separating iron and bonding agents used in baking pellets), and if the process is interrupted, these may be wasted.

Language in union contracts/arbitration awards. Having machines run more continuously was recognized as an important goal of work rule changes. For example, consider this excerpt from a section introducing new work rules in the National Pellet Mine's Basic Labor Agreement with the USW: "The parties recognize that most mining equipment is in a non-production mode for a significant amount of time each day. Minimizing this lost time is essential to improve productivity ..." (p. 170).

Another work practice (not discussed above) that reduced the speed of the mine was mine equipment relief practices. Before the crisis, changes in work shifts occurred at the "dry," located at a fixed point in the mine. Management requested that relief practices be changed to "eyeballto-eyeball," that is, at the equipment. ${ }^{59}$ Machines would then not stand idle for the time it took to travel to and back from the dry (perhaps as much as 15 to 30 minutes or longer of an eight-hour shift). The union at Minntac opposed the change in relief practices, but the arbitrator sided with management noting that "the alternate proposal by the Union ... would result in less production

\footnotetext{
${ }^{59}$ For example, before the crisis, a small van would drive to a mining truck, pick up its current driver, return him or her to the "dry," pick up the new driver, and return him or her to the idling truck. Under eyeball-to-eyeball relief, the new driver is brought to the truck when the old driver is replaced.
} 
than under the Company's proposal."

Robe River again. As mentioned, the new management at Robe River discussed the impact of changes in work practices. They emphasized large improvements in $Y_{t} / K_{t}$ and $Y_{t} / M_{t}$ following the changes. They argued that changes in work practices meant that "with better working methods the existing equipment could give the production levels needed, and that the move to a new mine site could be delayed," so that "huge savings have been made in capital expenditure, as well as in operating [materials] costs." 60

\section{Conclusion}

Following a dramatic increase in foreign competition in the early 1980s, the U.S. and Canadian iron ore industries both significantly increased labor, materials, and capital productivity. Conventional factors like closing of low productivity mines and adopting new technology account for only a small part of these productivity gains. Instead, changes in work practices drove the bulk of the productivity increases.

The work practices studied here are by no means peculiar to iron ore. They exist to varying degrees throughout many U.S. manufacturing, transportation, and other industries. And when competition has intensified in these industries, restrictive work practices have been loosened. What is peculiar to iron ore is that the entire industry was severely threatened. The U.S. auto industry, for example, experienced increased competitive pressure in the early 1980s, though only some segments were hit. These segments did change work practices somewhat. ${ }^{61}$ The U.S. Class I railroad industry experienced both truck and train deregulation in the 1980s. However, there has been little loosening of restrictive work practices in this industry, suggesting that the increase in competitive pressure was not that great.

\footnotetext{
${ }^{60}$ These two quotes are from "Robe River Revisited" and "Robe River Affair," respectively.

${ }^{61}$ Luria (1986) says, "The pressures for change are clearly uneven. Restrictive work rules and narrow classifications have lasted longer in those sectors of the industry that can best withstand foreign competition and outsourcing competition - for example, in plants that assemble large cars and trucks ..." (p. 24).
} 
Prescott (1998) talks about the need for developing a theory of TFP. ${ }^{62}$ This paper, I think, has made some progress in this endeavor: I have shown increases in competition (or decreases in tariffs) led to surges in TFP through changes in restrictive work practices. This naturally leads to the question, Why were restrictive work practices not changed before the crisis in iron ore? And why do they persist today in nearly full force in Class I railroads? Let me start with a straw man. This straw man says these work practices were part of a rent package received by workers. In this view, work practices led to idle time that was valued by the workers. In other words, workers used some of their rents to purchase idle time and other nonpecuniary benefits. With increased competition, rents were destroyed; hence, work practices had to be changed.

But this view is vastly incomplete, if there's much truth to it at all. If it was idle time workers wanted, why structure work practices so that machinery sat idle as well? With machinery idle, capital productivity and materials productivity suffer. Work practices clearly led to money being flushed down the toilet. I can't say this loud enough. Hence, there are other reasons these work practices were not changed before the crisis.

What are these other reasons? I mention two possibilities. It is beyond the scope of this paper to do more. Money can obviously be made by changing such work practices. But there may be disagreements among groups (for example, workers vs. local managers, repair workers vs. other workers) about how to divide the money. And, of course, there may be commitment problems. Can groups be assured that agreements will be honored? Also, might an "outside" group, like the local towns, say, through increased taxation, attempt to capture some of the gains? Many steel companies today, in fact, are trying to dump pension obligations made to early retirees in the 1980s. Of course, whatever the reason work practices were not changed, with competition, it may no longer be possible to flush money down the toilet and survive (as was the case here), and restrictive work

\footnotetext{
${ }^{62}$ See also Caselli and Coleman (2000), Chari, Kehoe, and McGrattan (1997), Klenow and Rodriguez-Clare (1997), Kocherlakota (2001), and Parente and Prescott (1999).
} 
practices must be changed. 


\section{Appendix A: Data Sources and Discussion}

In this appendix, I present sources of data and discuss data issues not addressed in the paper.

Pig iron statistics (used in Figure 1) are from the Minerals Yearbook of the United States (various issues), United States Geological Survey (USGS).

For the Minnesota pellet industry, production data (in tons) by mine are from the Minnesota Department of Revenue. Hours data for a mine are from the mine inspectors in each Minnesota county where mines are located (primarily St. Louis County). Some mines have operations in two counties (the pit and the mill can be in separate counties), so for these mines, hours figures are combined. These tons and hours statistics are used in Figures 2, 7, and 10, and Table 2. For the entire U.S. iron ore industry, production (in tons) and hours worked (used in Figure 3) are from the Minerals Yearbook of the United States. The U.S. Department of Labor's Bureau of Labor Statistics (BLS) publishes a productivity series ("Productivity Measures for Selected Industries and Government Services," Bulletin 2406, April 1992) where output is revenue divided by a price deflator. The BLS productivity series looks very much like the Minerals Yearbook series. For the Canadian industry, I have production (in tons) from Natural Resources Canada (NRC) for 1970-97. Statistics Canada has a deflated industry revenue series for 1981-97. For my measure of gross output in Figure 4, I used tons produced from 1970 to 1981 and then deflated industry revenue from 1981 to 1997. From 1981 onward, deflated industry revenue falls a bit less than tons produced (since pellets, the highest-quality ore, increase as a share of output in the 1980s). Hours worked (used in Figure 4) are from Statistics Canada.

Statistics Canada has time series for real capital stock, real capital services, and real materials purchases. The latter two series (used in Figure 5) run from 1981 to 1997. Wulong Gu provided this information. Input's share of revenues (used in Figure 6 and Table 1) is from Statistics Canada. I have used capital services in constructing TFP. Capital services falls 14 percent between 1981 and 1988. The capital stock calculated using geometric depreciation falls 29 percent between 1981 and 
1988. So, the increase in TFP would obviously have been more significant using the latter series. Price of new capital, price of labor (that is, compensation per hour), and capital stock (used in Figure 8) are from Statistics Canada. Usage and price of electricity (used in Figure 9) are from NRC. The data for Robe River are from Robe River Associates.

An issue not discussed in the paper is the extent to which mine workers produce output that is distinct from iron ore. In particular, some mines during the 1960s and 1970s generated some of their own electricity. Self-generated electricity was always a small share of total electricity use; its share fell throughout the 1970s, so that by the 1980s all electricity was purchased. Let $Y_{E}$ and $Y_{I}$ denote the (real) gross output of electricity generated and iron produced at the mines, respectively, and $N_{E}$ and $N_{I}$ the hours worked in electricity generation and iron ore production. I have presented information on $Y_{I} /\left(N_{E}+N_{I}\right)$. Data on self-generated electricity $Y_{E}$ are available in the U.S. Census of Mineral Industries at five-year intervals, but data on $N_{E}$ are not. Presumably, $N_{E}$ went to zero as $Y_{E}$ did. If I had data on $N_{E}$, and hence could plot $Y_{I} / N_{I}$, Figures 2 and 3, say, would look as follows. Productivity in the early 1970s would be a little "higher" than currently and would decrease a bit through the 1970s. The 1980s would be unchanged. This same logic applies to any construction activity that was occurring at the mines where mine staff were involved. That is, construction was happening in the 1970s and not the 1980s. This activity was scaled back in the 1970s.

\section{Appendix B: Materials Usage in the U.S. Iron Ore Industry}

The lowest level of aggregation in which a (real) materials series is constructed is the metal mines industry. Still, the Census of Mineral Industries provides an extensive accounting of materials usage in the iron ore industry every five years. Materials spending in the CMI is the sum of (1) electricity and fuel, (2) supplies, and (3) contracting out. Table B1 shows the spending on materials in the U.S. industry by these three groups (and some breakdown within groups) in 1982 and 1987. Electricity and fuel, supplies, and contracting out amounted to 55.8, 41.3, and 2.9 percent of materials, respectively, in 1982. The same shares in 1987 were 53.7, 40.7, and 5.6 percent. So, 
there was only a small change in the share of materials spending among these three groups.

In addition to the spending on materials, the CMI also gives the quantity of materials purchased for (essentially) each material in the electricity and fuel group, plus a few in the supplies group (explosives, bentonite, and so on). Between 1982 and 1987, the CMI reports that tons of iron ore produced increased 45 percent. In the electricity and fuel group, the quantity of fuel for vehicles (primarily diesel) fell over 15 percent between 1982 and 1987. The quantity of fuel for furnaces increased only slightly (about 3 percent). Hence, tons per unit of both fuels soared. Electricity usage actually increased a bit faster than tons from 1982 to 1987; hence, there was a small decrease in tons per unit of electricity. These same patterns are found in Canada during the 1980s. To estimate real materials growth between 1982 and 1987, I need to make assumptions about how prices of supplies changed between the dates. Recall that I have quantities for electricity and fuel. Under the assumption that there were no price changes for supplies between these dates, I estimate that U.S. materials productivity $(Y / M)$ increased 23 percent. Details on this calculation, and Table B1's construction, are available from me.

\section{Appendix C: Work Practices and Productivity: Theory}

Here I briefly sketch the arguments of Section 5 more formally.

Consider the fireman case. Let the number of firemen and other railroad workers be denoted by $n_{f}$ and $n_{p}$ (" $p$ " for production). Total employment is $n=n_{p}+n_{f}$. Work practices require that $n_{f} \geq \lambda$ (where $\lambda$ is typically one). Production can then be modeled as

$$
y=\bar{A}\left(n_{p}\right)^{\theta_{n}} m^{\theta_{m}} k^{\theta_{k}}
$$

if $n_{f} \geq \lambda$, and $y=0$ if $n_{f}<\lambda$ (that is, the train isn't permitted to run). Note that only $n_{p}$ enters as the labor input when the train runs. Labor and materials productivity are (assuming $n_{f}=\lambda$ )

$$
\frac{y}{n}=\bar{A}\left(\frac{n_{p}}{n}\right)^{\theta_{n}}\left(\frac{m}{n}\right)^{\theta_{m}}\left(\frac{k}{n}\right)^{\theta_{k}} ; \quad \frac{y}{m}=\bar{A}\left(\frac{n_{p}}{m}\right)^{\theta_{n}}\left(\frac{k}{m}\right)^{\theta_{k}}
$$

where $n=n_{p}+\lambda$. Suppose the work practice is loosened, that is, $\lambda$ falls. Here it seems reasonable 
to assume that the railroad would make no changes in other inputs $\left(n_{p}, m, k\right)$. Labor productivity increases. Materials productivity doesn't change.

Consider a model of the iron ore case. Take a given time period, say, a week, and divide it into $L$ equal subperiods, say, hours. Suppose mine inputs over a subperiod are denoted $\left(\widetilde{n}_{r}, \widetilde{n}_{p}, \widetilde{m}, \widetilde{k}\right)$, where $\widetilde{n}_{r}$ and $\widetilde{n}_{p}$ are repair and production worker hours, respectively. Mines are either in operating mode in a subperiod, with output $\widetilde{y}=\widetilde{A} f\left(\widetilde{n}_{p}, \widetilde{m}, \widetilde{k}\right)$, where $f(\cdot)=F(\cdot)$ as in equation (2), or because of breakdowns, in non-operating mode, with no output produced. Suppose that a mine cannot change its labor or capital inputs over the given period (that is, the week). It may be able to change its material input. I assume a non-operating mine consumes materials $\mu \widetilde{m}$, where $\mu \in[0,1]$. If the mine operates $l$ subperiods, output over the period is $l \widetilde{y}$. Denote the fraction of time the mine operates by $\alpha=l / L$. I assume this fraction depends on the repair staff and work practice regime.

Think of the restrictive work practice regime as precluding machine operators from performing simple tasks to restart machines (tasks they could accomplish). In this regime, then, mines hire repair staff to complete these simple tasks. I denote hours by these repair workers by $\widetilde{n}_{f}$. (I use " $f$ " to denote similarity with the fireman case.) I denote the inputs used over the entire period (that is, the week) by $\left(n_{f}, n_{r}, n_{p}, m, k\right)=\left(L \widetilde{n}_{f}, L \widetilde{n}_{r}, L \widetilde{n}_{p},[l+(L-l) \mu] \widetilde{m}, L \widetilde{k}\right)$. I assume that $\alpha=\alpha\left(n_{r}, \omega, n_{f}\right)$, where $\omega \in\{0,1\}$ denotes the work practice regime ( $\omega=0$ denoting no restrictive work practices; $\omega=1$, the restrictive regime). I assume $\alpha(\cdot)$ satisfies (1) increasing in $n_{r} ;(2)$ if $\omega=0$, then $\alpha\left(n_{r}, \omega, n_{f}\right)$ does not depend on $n_{f}$ (that is, adding more repair staff to complete simple tasks does not increase the speed of the system); (3) if $\omega=1$, then $\alpha\left(n_{r}, \omega, n_{f}\right)$ increases in $n_{f}$; but (4) $\alpha\left(n_{r}, 1, n_{f}\right)<\alpha\left(n_{r}, 0,0\right)$ for all $n_{f}$ (that is, the speed of the system with $\omega=1$ is always less than with $\omega=0)$. Production is then

$$
y=\widetilde{A} \frac{\alpha}{[\alpha+(1-\alpha) \mu]^{\theta_{m}}}\left(n_{p}\right)^{\theta_{n}} m^{\theta_{m}} k^{\theta_{k}}
$$


where, again, $\alpha=\alpha\left(n_{r}, \omega, n_{f}\right){ }^{63}$ Labor and materials productivity are

$$
\frac{y}{n}=\widetilde{A} \frac{\alpha}{[\alpha+(1-\alpha) \mu]^{\theta_{m}}}\left(\frac{n_{p}}{n}\right)^{\theta_{n}}\left(\frac{m}{n}\right)^{\theta_{m}}\left(\frac{k}{n}\right)^{\theta_{k}} ; \frac{y}{m}=\widetilde{A} \frac{\alpha}{[\alpha+(1-\alpha) \mu]^{\theta_{m}}}\left(\frac{n_{p}}{m}\right)^{\theta_{n}}\left(\frac{k}{m}\right)^{\theta_{k}}
$$

where $n=n_{f}+n_{r}+n_{p}$.

Consider the impact of loosening work practices, that is, reducing $\omega$. The mine clearly reduces $n_{f}$ to zero (from, say, an initial value of $L \widetilde{n}_{f}=\lambda$, to mirror the overstaffing parameter in the fireman case). As an approximation, suppose the mine makes no changes in its other inputs $\left(\widetilde{n}_{r}, \widetilde{n}_{p}, \widetilde{m}, \widetilde{k}\right)$. Labor productivity increases since $n$ decreases and $\alpha(\cdot)$ increases. There is both less overstaffing and greater production. Now, materials productivity increases. ${ }^{64}$

Note that changes in work practices increase labor productivity in (4) through three sources: $\widetilde{A} \alpha[\alpha+(1-\alpha) \mu]^{-\theta_{m}}\left(n_{p} / n\right)^{\theta_{n}},(m / n)^{\theta_{m}}$, and $(k / n)^{\theta_{k}}$ (that is, through increases in TFP, materials per hour, and capital per hour). That is, changes in work practices yield time series like Figure 6.

\footnotetext{
${ }^{63}$ This follows from $y=l \widetilde{y}=l \widetilde{A} f\left(\widetilde{n}_{p}, \widetilde{m}, \widetilde{k}\right)=l \widetilde{A} f\left(\frac{n_{p}}{L}, \frac{m}{[l+(L-l) \mu]}, \frac{k}{L}\right)=\alpha \widetilde{A} f\left(n_{p}, \frac{m}{[\alpha+(1-\alpha) \mu]}, k\right)$.

${ }^{64}$ Whether or not materials productivity increases does depend on parameter values and functional form assumptions. If $\mu=1$, then $y / m=\widetilde{A} \alpha\left(n_{p} / m\right)^{\theta_{m}}(k / m)^{\theta_{k}}$, and loosening work practices clearly increases $y / m$. In the Cobb-Douglas case, $y / m$ may increase even if $\mu=0$.
} 


\section{References}

Aydin, Hamit, and John E. Tilton. 2000. "Mineral Endowment, Labor Productivity, and Comparative Advantage in Mining." Resource and Energy Economics 22 (October): 281-93.

Borenstein, Severin, and Joseph Farrell. 1999. "Do Stock Price Movements Reveal Profit Dissipation? An Investigation of the Gold Mining Industry." Working Paper no. 7075 (April). Cambridge, Mass.: NBER.

Bridgman, Benjamin, and James A. Schmitz, Jr. 2004. "What Determines Productivity? Lessons From the U.S. Sugar Manufacturing Industry Following the Introduction of High Fructose Corn Syrup." Manuscript. Minneapolis, Minn.: Federal Reserve Bank of Minneapolis.

Caselli, Francesco, and Wilbur John Coleman II. 2000. "The World Technology Frontier.” Working Paper no. 7904 (September). Cambridge, Mass.: NBER.

Chari, V. V., Patrick J. Kehoe, and Ellen R. McGrattan. 1997. "The Poverty of Nations: A Quantitative Investigation." Research Department Staff Report no. 204. Federal Reserve Bank of Minneapolis.

Clark, Gregory. 1987. "Why Isn't the Whole World Developed? Lessons From the Cotton Mills." Journal of Economic History 47 (March): 141-73.

Davis, Edwin. 1964. Pioneering with Taconite. St. Paul, Minn.: Minnesota Historical Society Press.

Galdón-Sánchez, José E., and James A. Schmitz, Jr. 2002. "Competitive Pressure and Labor Productivity: World Iron-Ore Markets in the 1980s." American Economic Review 92 (September): $1222-35$.

Hellmer, Stefan. 1977. "Competitive Strength in Iron Ore Production." Ph.D. thesis. Luleå, Sweden: Luleå University.

Holmes, Thomas J., and James A. Schmitz, Jr. 2001. "Competition at Work: Railroads vs. Monopoly in the U.S. Shipping Industry." Federal Reserve Bank of Minneapolis Quarterly 
Review 25 (Spring): 3-29.

Ichniowski, Casey, Kathryn Shaw, and Giovanna Prennushi. 1997. "The Effects of Human Resource Management Practices on Productivity: A Study of Steel Finishing Lines." American Economic Review 87 (June): 291-313.

Klenow, Peter J., and Andres Rodriguez-Clare. 1997. In NBER Macroeconomics Annual 1997, vol. 12. Cambridge, Mass.: MIT Press.

Kocherlakota, Narayana. 2001. "Building Blocks for Barriers to Riches." Research Department Staff Report no. 288. Federal Reserve Bank of Minneapolis.

Learmont, Mary. 1983. "Taconite Operations on the Mesabi Range: Preliminary Report." Minneapolis, Minn.: Mineral Resources Research Center, Department of Civil and Mineral Engineering, University of Minnesota.

Luria, Daniel D. 1986. "New Labor-Management Models From Detroit?" Harvard Business Review 64 (September/October): 22-27.

MacDonald, James M. 1994. "Does Import Competition Force Efficient Production?" Review of Economics and Statistics 76 (November): 721-27.

Marcus, Peter F., and Karlis M. Kirsis, with Peter J. Kakela. 1987. "The Threatened North American Iron Ore Industry: Breakthrough Analysis." World Steel Dynamics Core Report Z, PaineWebber Incorporated.

Markiewicz, Kira, Nancy Rose, and Catherine Wolfram. 2004. "Does Competition Reduce Costs? Assessing the Impact of Regulatory Restructuring on U.S. Electric Generation Efficiency." Working Paper no. 11001 (December). Cambridge Mass.: NBER.

Nickell, Stephen J. 1996. "Competition and Corporate Performance." Journal of Political Economy 104 (August): 724-46.

Parente, Stephen L., and Edward C. Prescott. 1999. "Monopoly Rights: A Barrier to Riches." American Economic Review 89 (December): 1216-33. 
Prescott, Edward C. 1998. "Needed: A Theory of Total Factor Productivity." International Economic Review 39 (August): 525-51.

Sivadasan, Jagadeesh. 2003. "Barriers to Entry and Productivity: Micro Evidence From Indian Manufacturing Sector Reforms.” Working paper. Chicago: University of Chicago.

Statistics Canada. Various years. "Fixed Capital Flows and Stocks: Methodology." Investment and Capital Stock Division, National Wealth and Capital Stock Division, Cat. No. 13-568.

Symeonidis, George. 2002. "The Effect of Competition on Wages and Productivity: Evidence From the UK." Working paper. University of Essex.

Syverson, Chad. 2003. "Market Structure and Productivity: A Concrete Example." Working paper. Chicago: University of Chicago. 
Table 1

Total Factor Productivity

Canadian Iron Ore Industry

\begin{tabular}{|c|c|c|c|c|}
\hline \multirow{2}{*}{ Year } & \multirow{2}{*}{$\begin{array}{l}\text { Total Factor } \\
\text { Productivity }\end{array}$} & \multicolumn{3}{|c|}{ Calculated From: } \\
\hline & & $Y_{t} / N_{t}$ & $\left(M_{t} / N_{t}\right)^{S_{M_{t}}}$ & $\left(K_{t} / N_{t}\right)^{S_{K_{t}}}$ \\
\hline 1981 & 1.00 & 1.00 & 1.00 & 1.00 \\
\hline 1982 & 0.91 & 0.94 & 0.98 & 1.06 \\
\hline 1983 & 0.86 & 0.97 & 1.06 & 1.07 \\
\hline 1984 & 0.91 & 1.09 & 1.14 & 1.05 \\
\hline 1985 & 1.00 & 1.19 & 1.08 & 1.10 \\
\hline 1986 & 1.33 & 1.61 & 1.09 & 1.11 \\
\hline 1987 & 1.34 & 1.64 & 1.05 & 1.16 \\
\hline 1988 & 1.46 & 1.78 & 1.10 & 1.11 \\
\hline 1989 & 1.48 & 1.79 & 1.08 & 1.12 \\
\hline 1990 & 1.36 & 1.57 & 1.04 & 1.11 \\
\hline 1991 & 1.40 & 1.64 & 1.06 & 1.11 \\
\hline 1992 & 1.41 & 1.58 & 1.01 & 1.11 \\
\hline 1993 & 1.50 & 1.59 & 1.00 & 1.06 \\
\hline 1994 & 1.54 & 1.75 & 1.05 & 1.07 \\
\hline 1995 & 1.51 & 1.64 & 1.02 & 1.06 \\
\hline
\end{tabular}


Table 2

Minnesota Pellet Industry

Decomposition of Industry Labor Productivity Growth

(All figures in percent)

\begin{tabular}{|c|c|c|c|c|c|}
\hline \multirow{3}{*}{$\begin{array}{c}\text { Growth Between } \\
1980 \text { and }\end{array}$} & \multirow{3}{*}{$\begin{array}{c}\text { Overall } \\
\text { Industry } \\
\text { Growth }\end{array}$} & \multicolumn{4}{|c|}{ Share of Industry Growth Due to: } \\
\hline & & Within & Between & Cross & Closing \\
\hline & & Mines & Mines & Mines & Mines \\
\hline 1981 & 10.20 & 105 & -16 & 11 & 0 \\
\hline 1982 & 0 & - & - & - & - \\
\hline 1983 & 13.60 & 79 & 16 & 5 & 0 \\
\hline 1984 & 55.10 & 93 & 6 & 1 & 0 \\
\hline 1985 & 67.90 & 97 & 3 & 0 & 0 \\
\hline 1986 & 77.50 & 87 & 7 & 6 & 0 \\
\hline 1987 & 121.50 & 77 & 3 & 14 & 6 \\
\hline 1988 & 108.80 & 76 & 3 & 15 & 7 \\
\hline 1989 & 101.80 & 73 & 3 & 16 & 7 \\
\hline 1990 & 100.90 & 95 & 7 & -2 & 0 \\
\hline 1991 & 87.20 & 96 & 9 & -5 & 0 \\
\hline 1992 & 91.70 & 92 & 9 & -1 & 0 \\
\hline 1993 & 104.40 & 108 & 6 & -13 & 0 \\
\hline 1994 & 113.70 & 106 & 6 & -12 & 0 \\
\hline 1995 & 119.90 & 101 & 6 & -7 & 0 \\
\hline
\end{tabular}

Notes: “-” means not defined (growth was zero between 1980 and 1982). Weights are mine’s share of industry hours. 
Table B1

Materials Spending in the U.S. Iron Ore Industry, 1982 and 1987

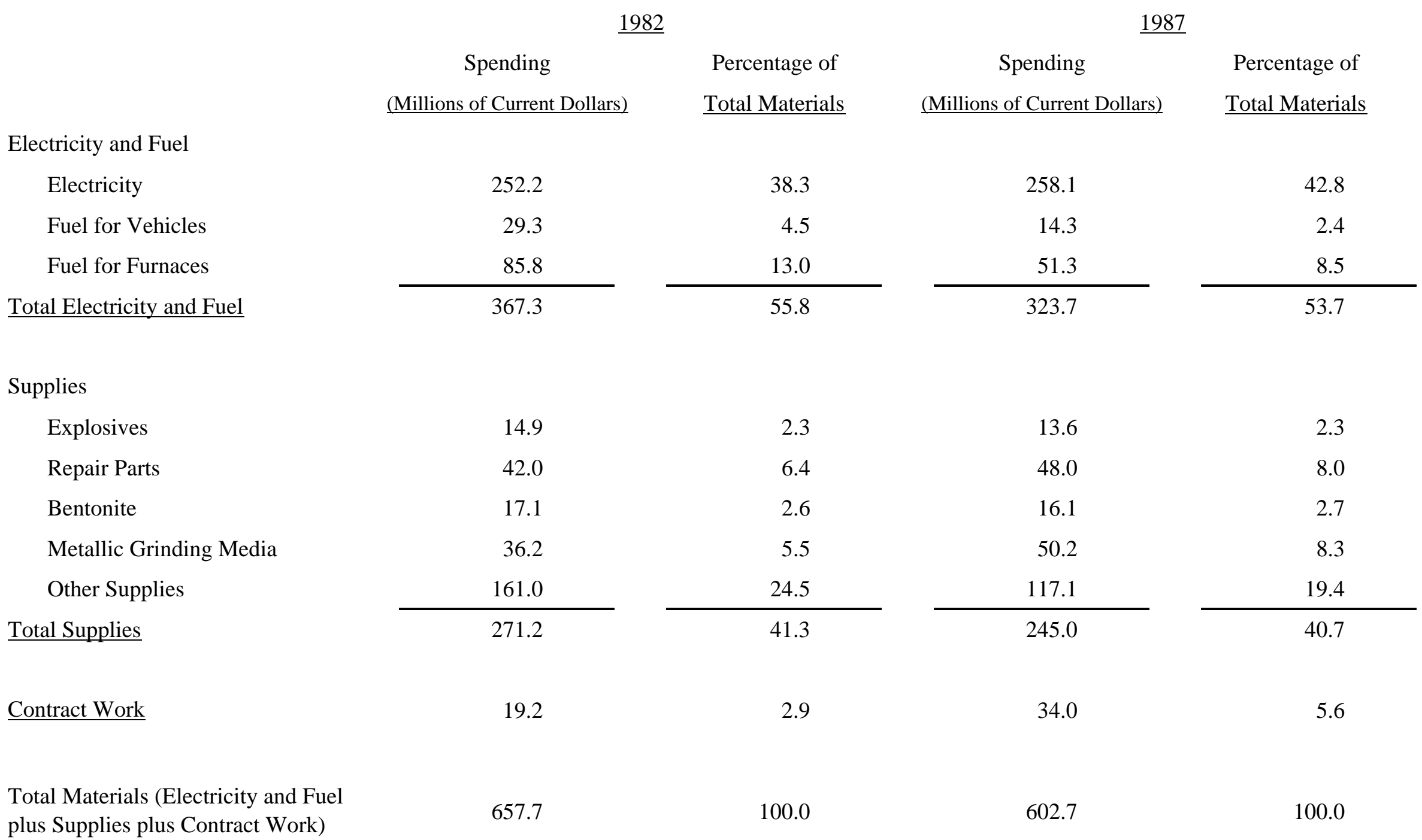


Figure 1:

Pig Iron Production By Various Regions, 1950-96

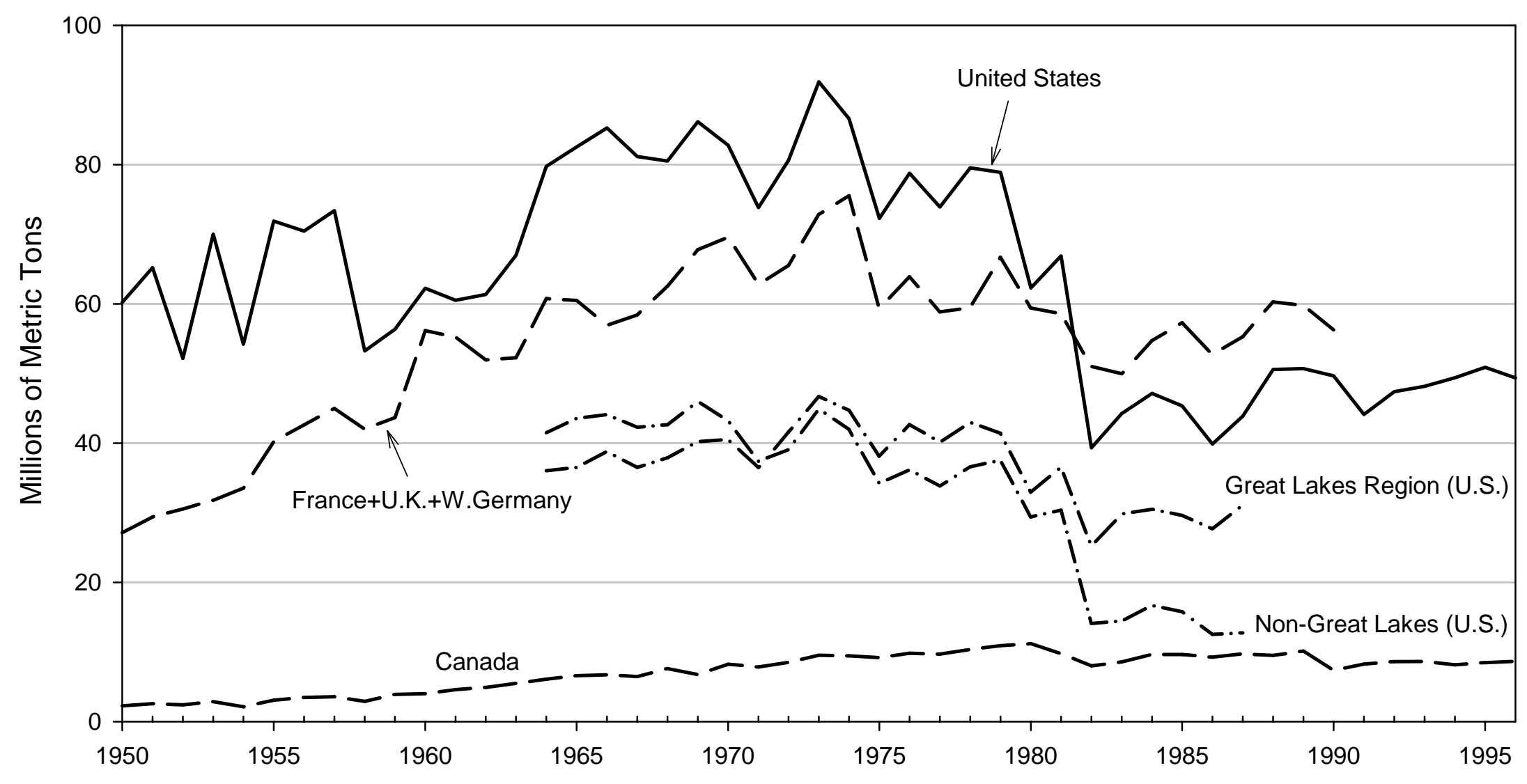


Figure 2:

Production and Labor Productivity: Minnesota Pellet Industry

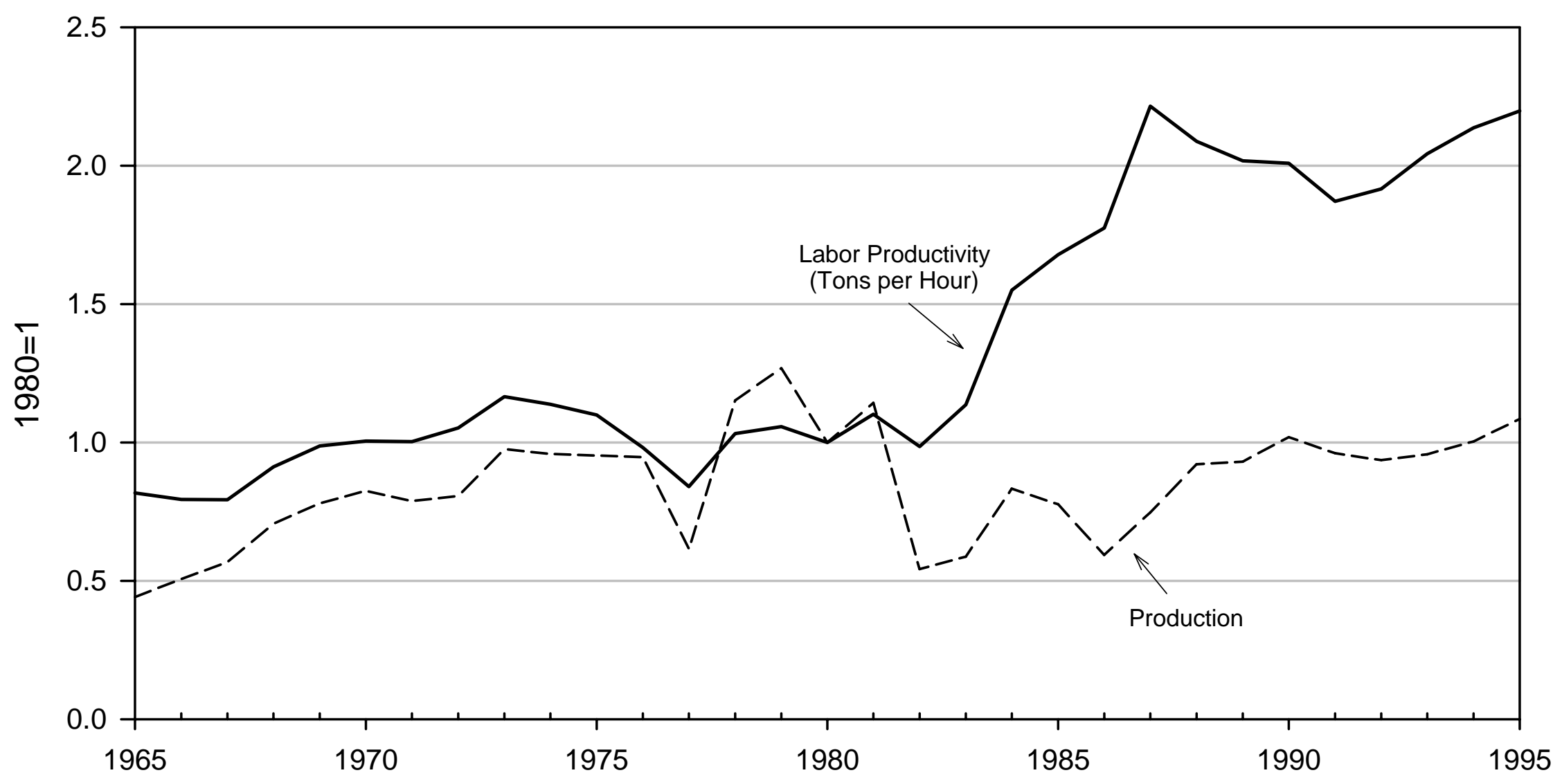




\section{Figure 3:}

Production and Labor Productivity: U.S. Iron Ore Industry

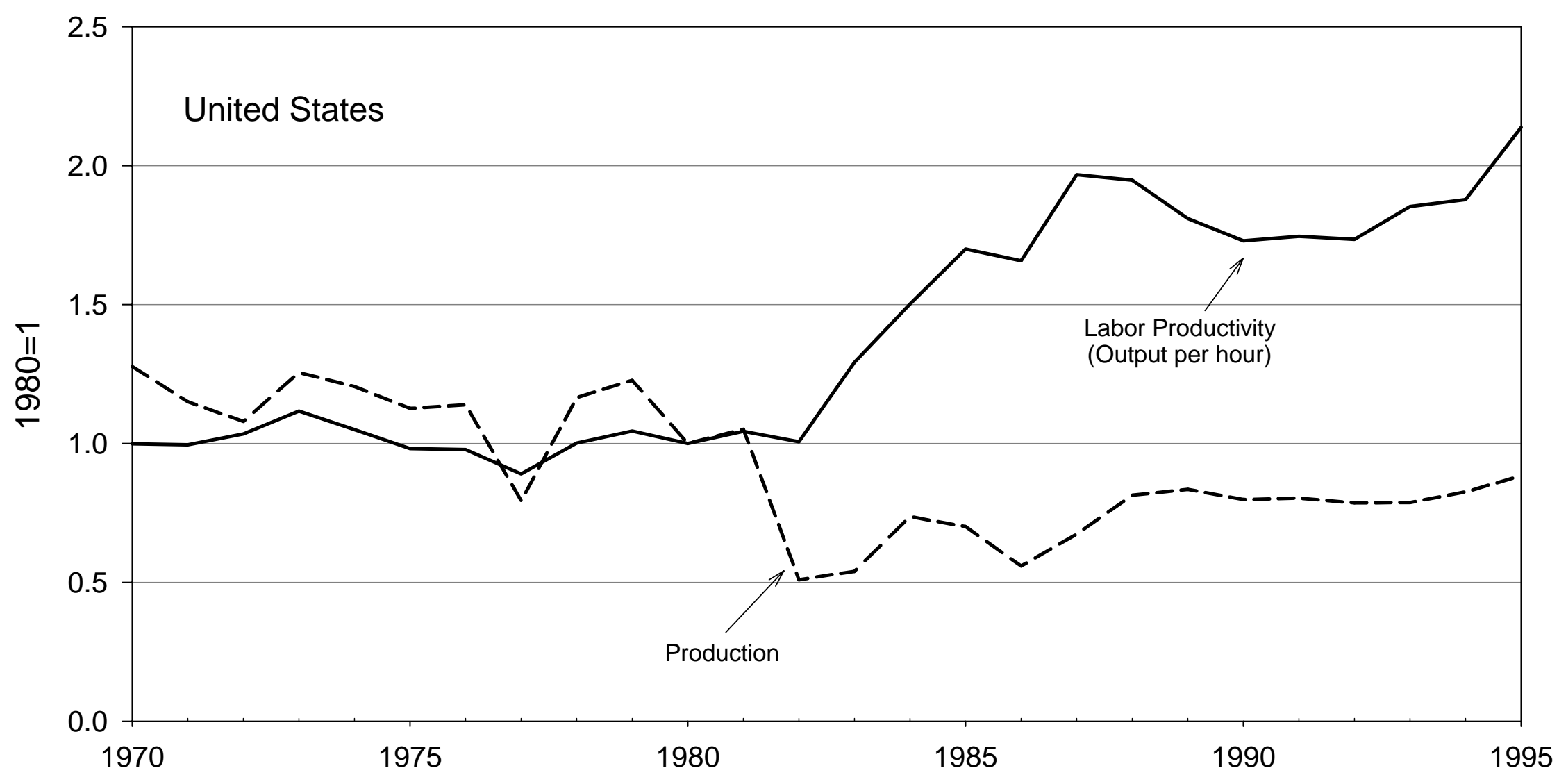


Figure 4:

Production and Labor Productivity: Canadian Iron Ore Industry

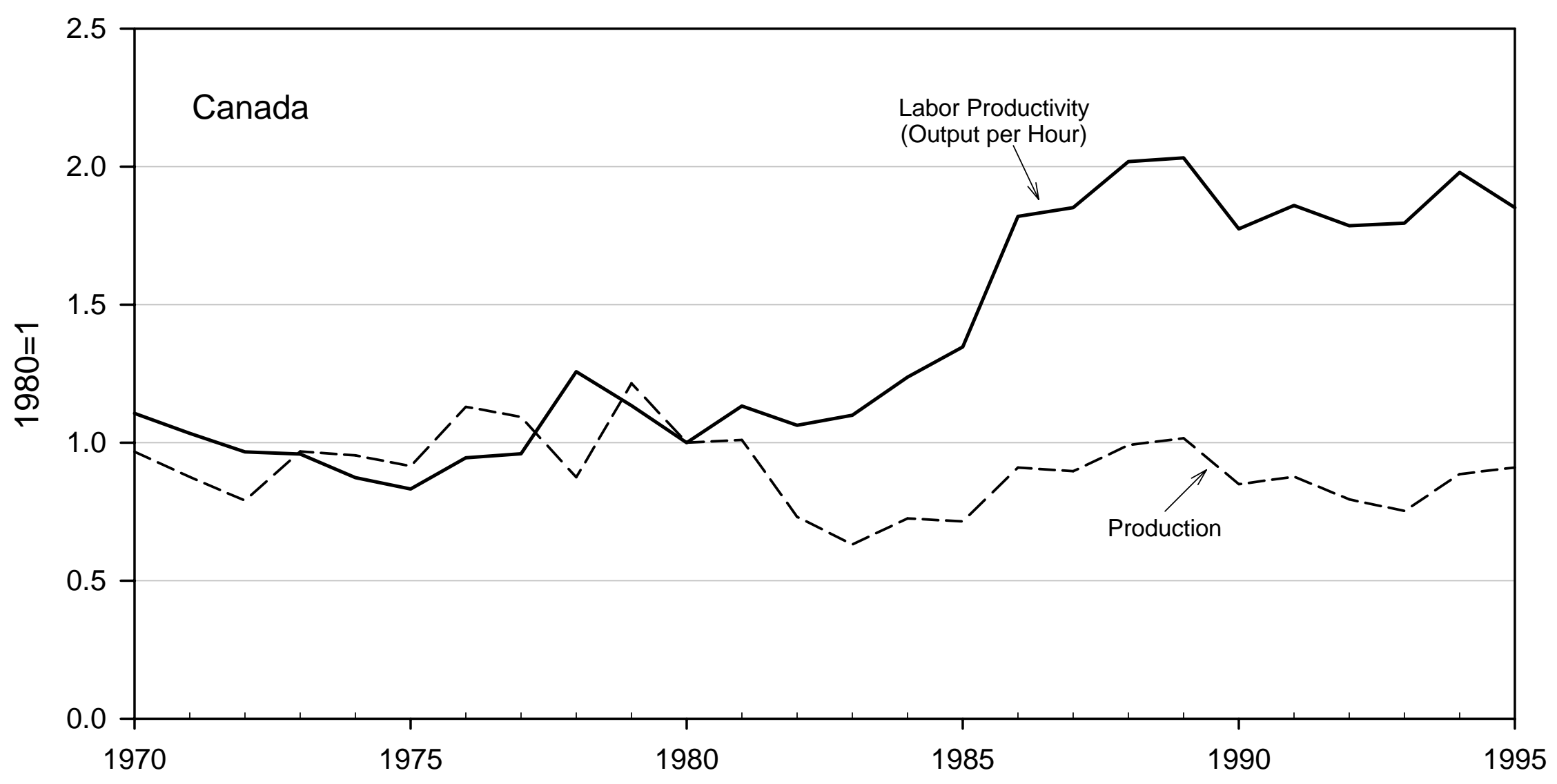


Figure 5:

Materials Productivity and Capital Productivity:

Canadian Iron Ore Industry

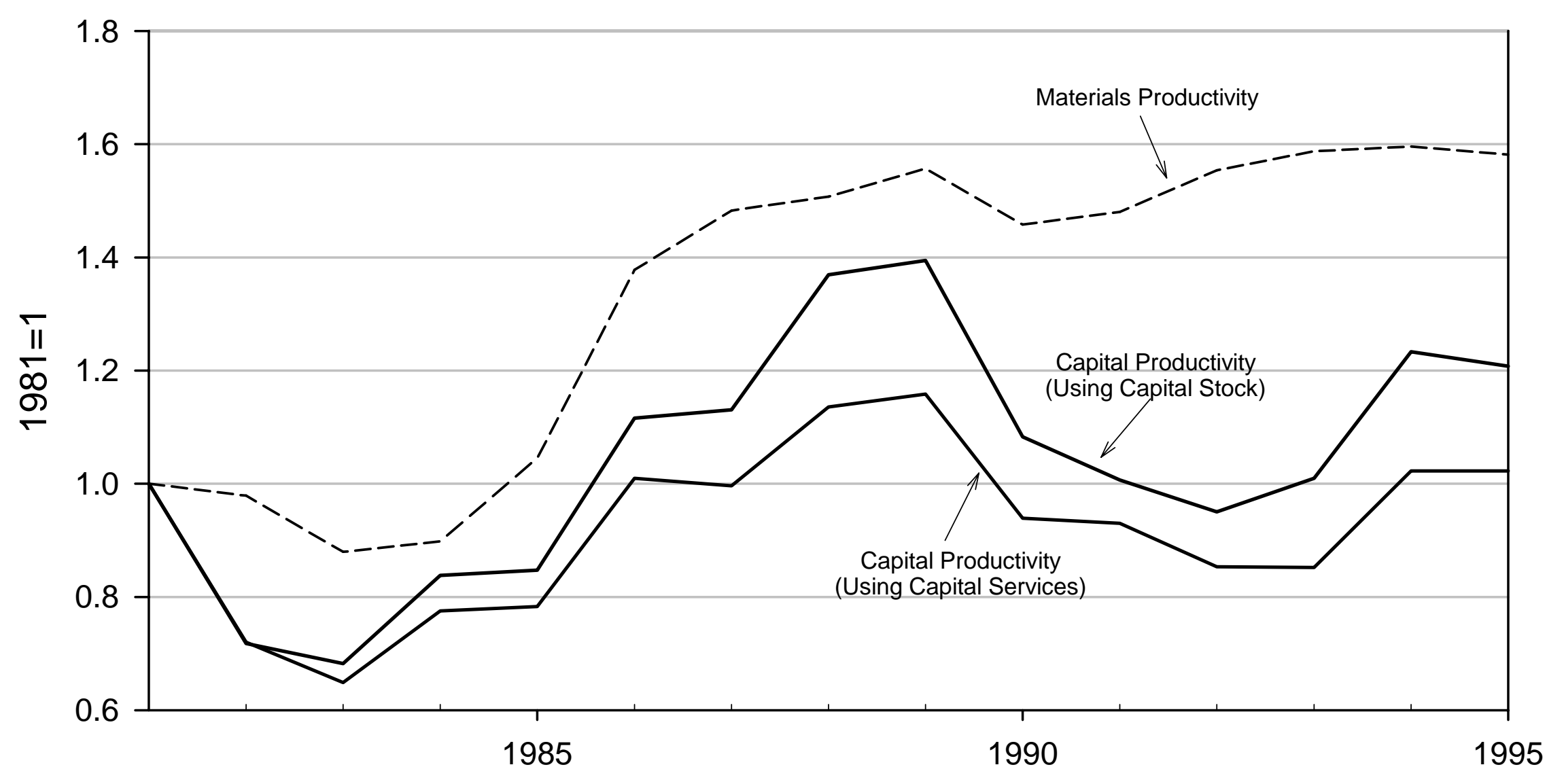


Figure 6:

Total Factor Productivity

(And Quantities Used in Its Calculation)

Canadian Iron Ore Industry

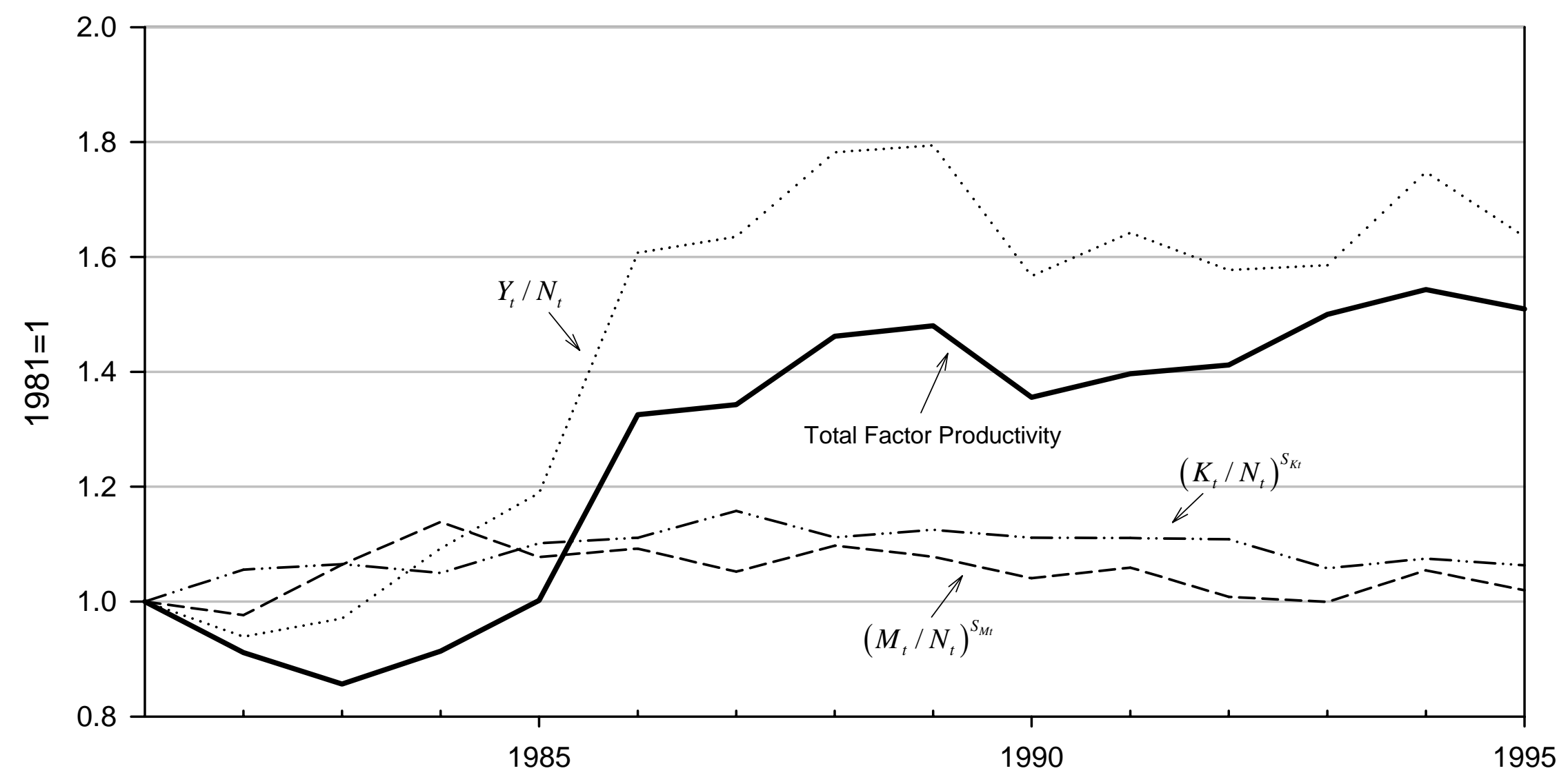


Figure 7:

Production and Labor Productivity

Minnesota Pellet Mines
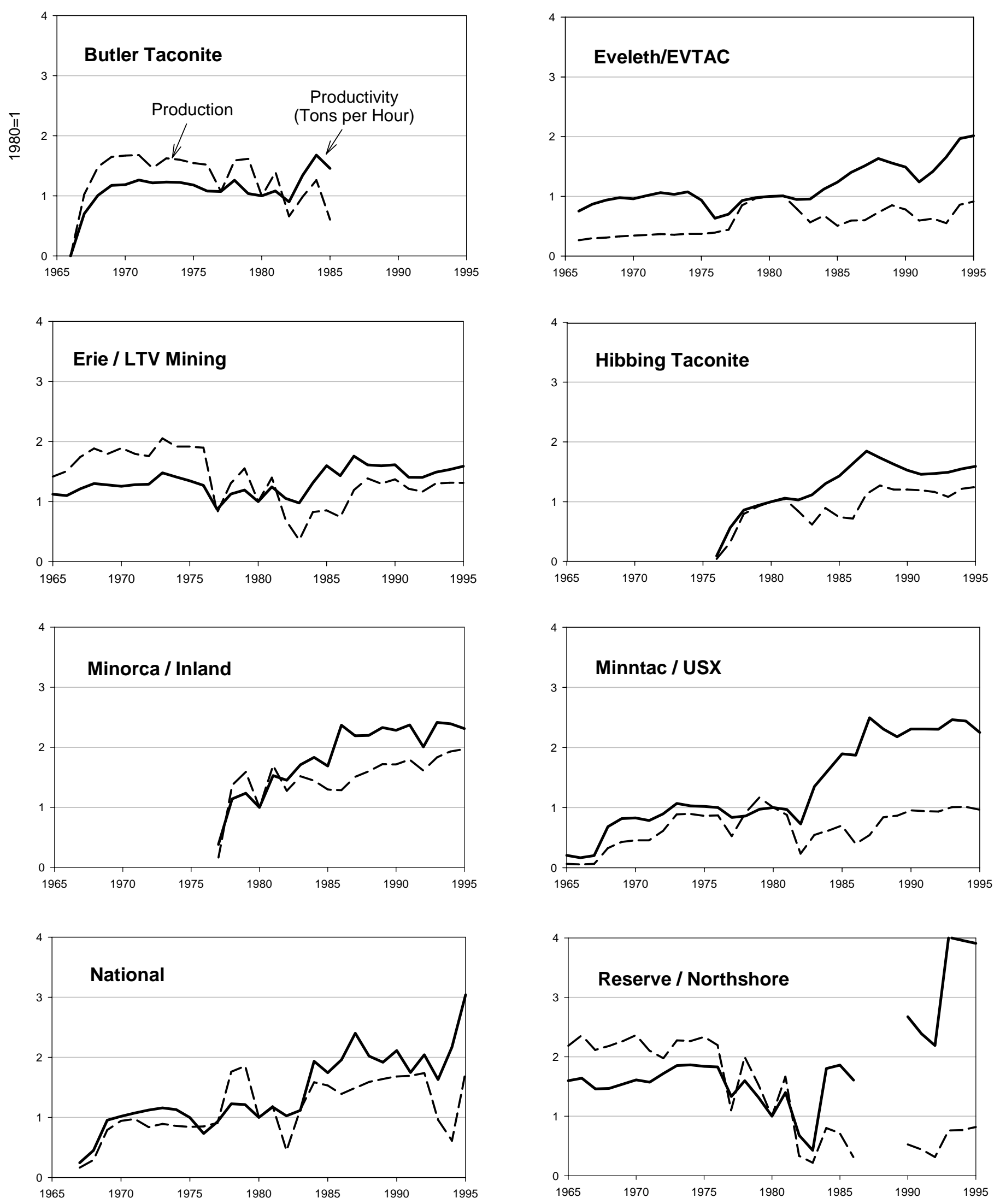
Figure 8:

Price of Labor Relative to Price of New Capital

vs. Capital Usage Relative to Labor Usage

Canadian Iron Ore Industry

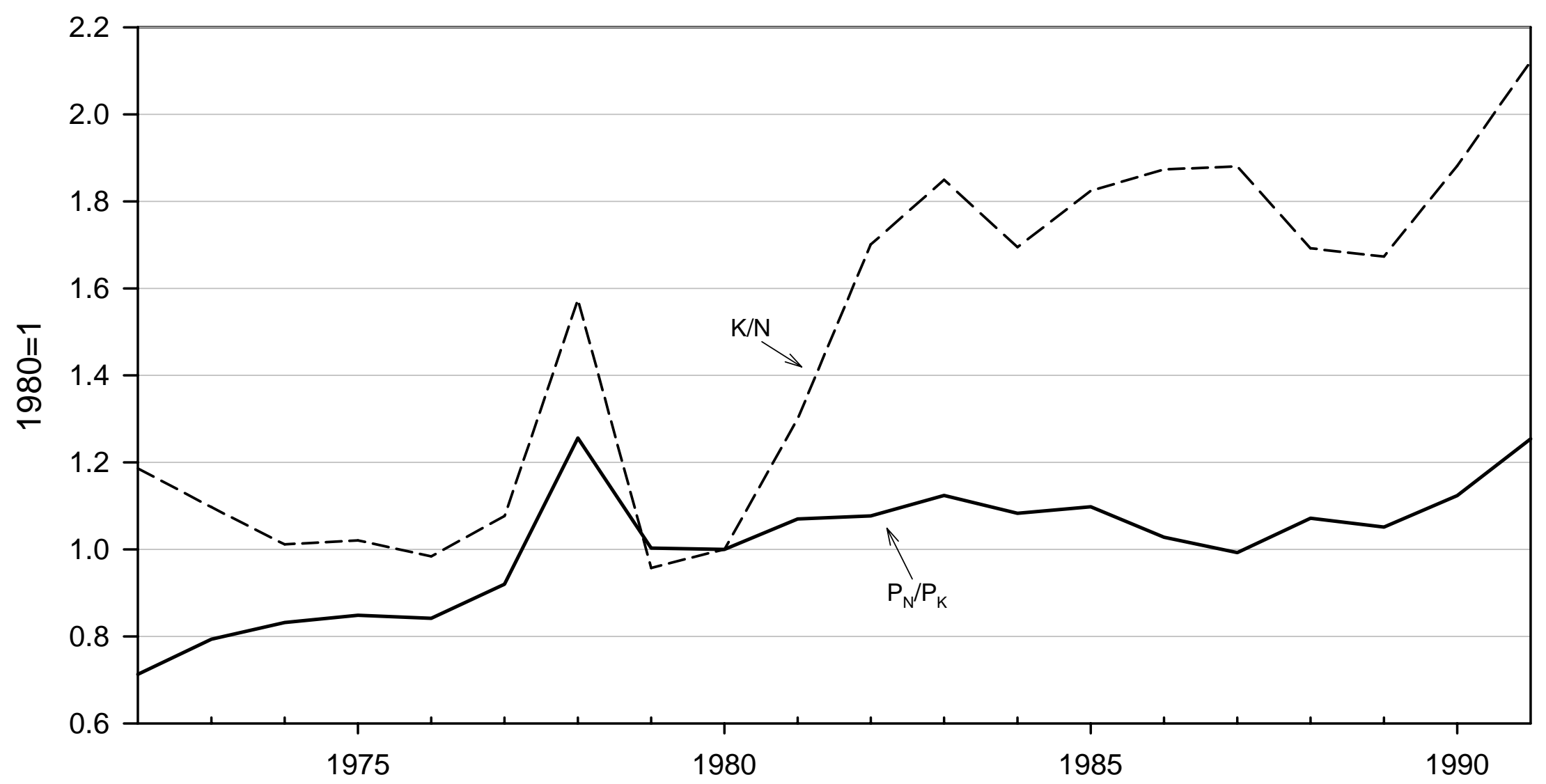


Figure 9:

Price of Labor Relative to Price of Electricity vs.

Electricity Usage Relative to Labor Usage

Canadian Iron Ore Industry

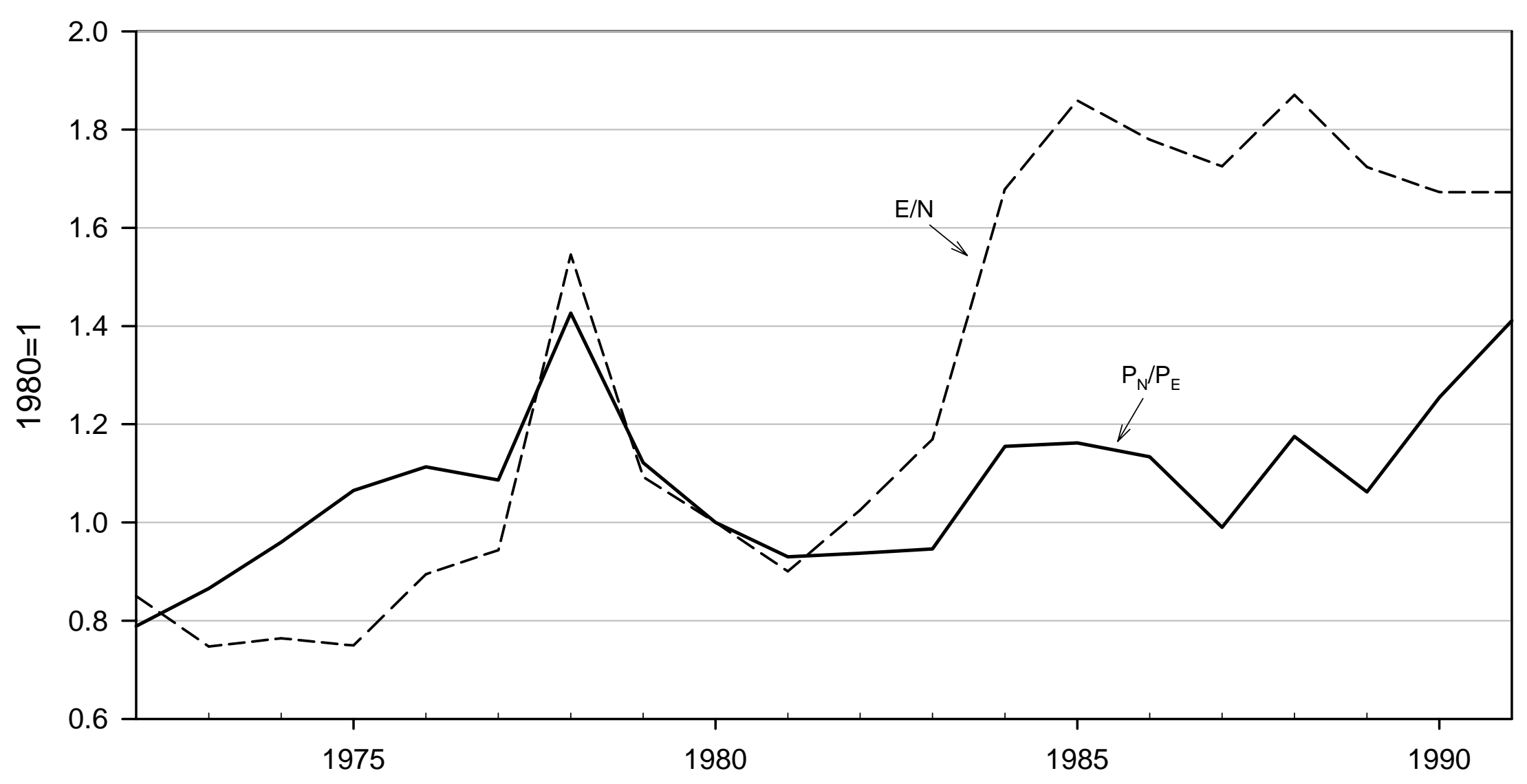


Figure 10:

Total Hours and Repair Hours as Percentage of Total Hours

Minntac/USX Pellet Mine

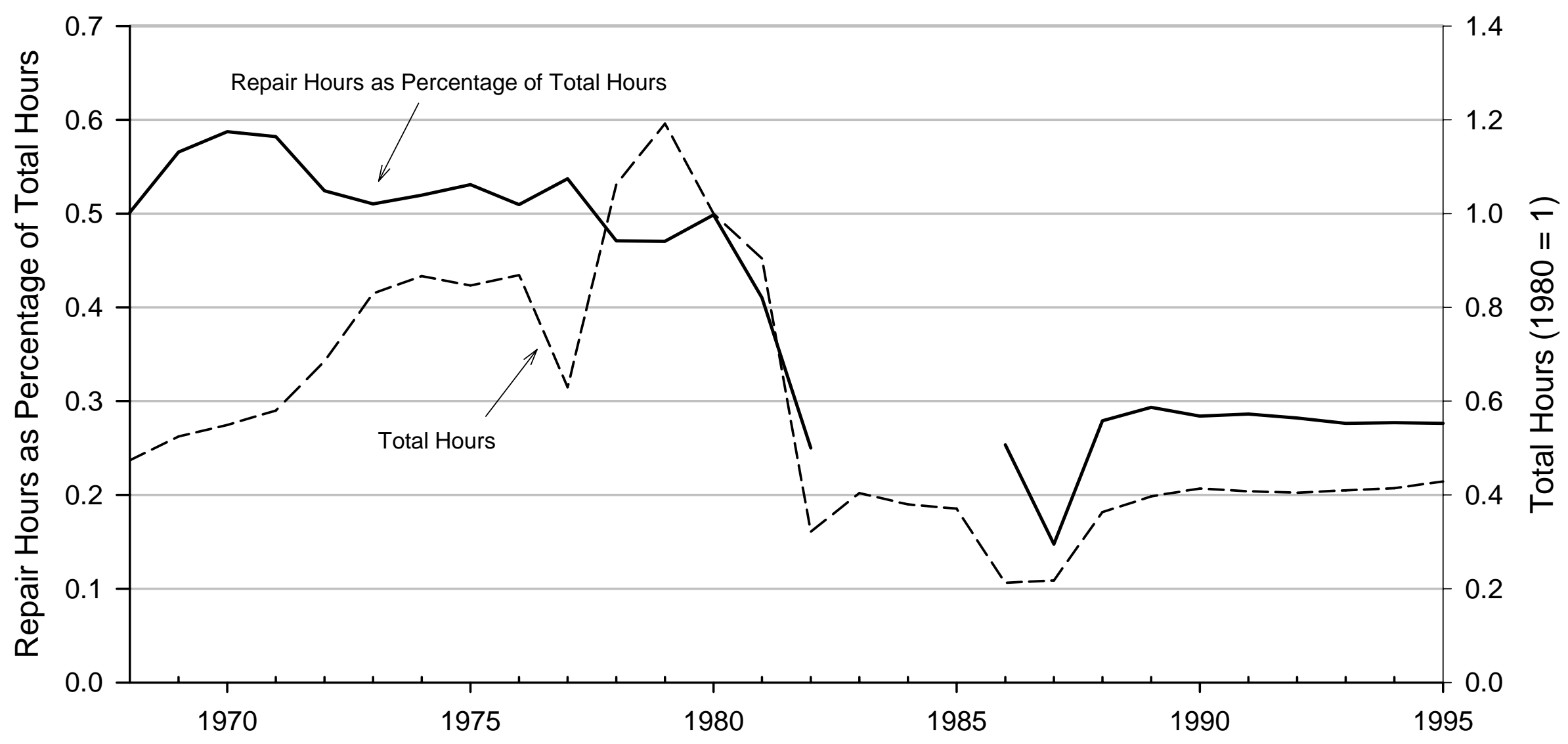


Figure 11:

Production And Labor Productivity: Robe River Iron Ore

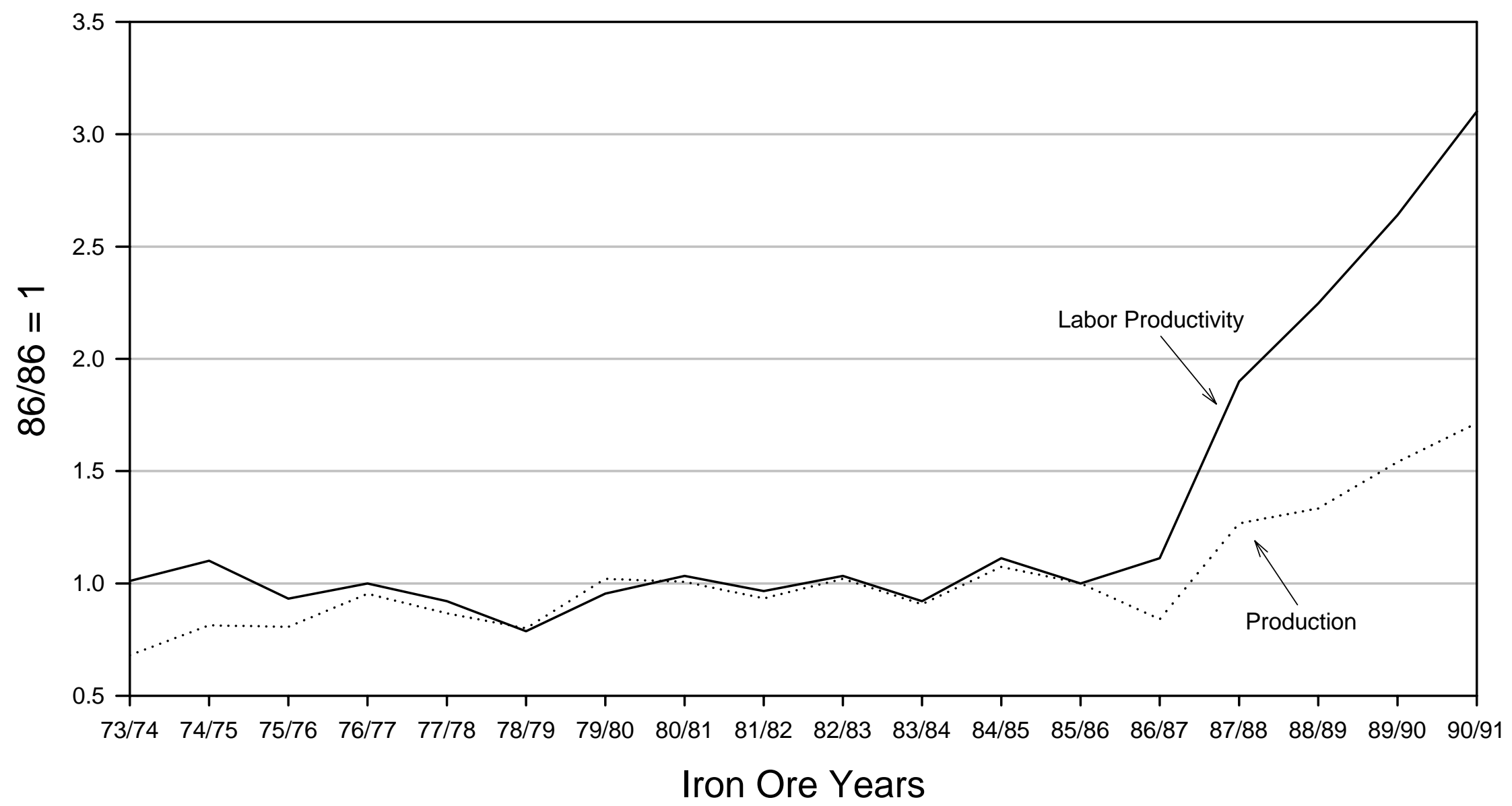

